\title{
THE DESIGN OF A QUICK RELEASE ATTACHMENT MECHANISM FOR A HYDROFOIL BOARD
}

\author{
By \\ Zarya O. Blackwood \\ Bachelor of Science Engineering, University of the West Indies, Trinidad \& Tobago (2017)
}

\author{
A project \\ presented to Ryerson University \\ in partial fulfilment of the \\ requirements for the degree of \\ Master of Engineering \\ in the program of \\ Aerospace Engineering
}

Toronto, Ontario, Canada, 2020

C Zarya O. Blackwood, 2020 


\section{AUTHOR'S DECLARATION FOR ELECTRONIC SUBMISSION OF A PROJECT}

I hereby declare that I am the sole author of this project. This is a true copy of the project, including any required final revisions.

I authorize Ryerson University to lend this project to other institutions or individuals for scholarly research.

I further authorize Ryerson University to reproduce this project by photocopying or by other means, in total or in part, at the request of other institutions or individuals for the purpose of scholarly research.

I understand that my project may be made electronically available to the public. 


\title{
THE DESIGN OF A QUICK RELEASE ATTACHMENT MECHANISM FOR A HYDROFOIL BOARD
}

\author{
Zarya O. Blackwood \\ Master of Engineering, Aerospace Engineering, Ryerson University, Toronto
}

(2020)

\section{ABSTRACT}

The primary objective of this project was to design a quick attach and detach system for use with a surfing foilboard. Foilboards are comprised of a board, mast, and fuselage, onto which wings are attached. These components are generally held together by long bolts, which makes the overall board tedious to assemble and disassemble. Research was conducted on the general concept of attaching components rigidly as well as on the market of current foilboard quick attach mechanisms, and a series of conceptual designs were created from it. All design concepts were rated using metrics generated from both the project objectives and market research, and the top-rated concept was then drawn up in Solidworks. Several design iterations were developed in order to meet both the minimum $300 \mathrm{~g}$ weight, tensile and compressive strength, and attachment/detachment speed requirements. The design iterations were first validated using a series of Solidworks simulation analyses. Subsequently the final design candidate was analysed using a series of ANSYS Static Structural simulations. The final design can withstand the loads and torques during regular usage as well as cases of the rider standing on the side of the mast while the board is at rest. The design can be attached or detached within one second. It can survive up to $8.769 \times 105$ cycles of maximum cyclical loading and is easy to clean. 


\section{TABLE OF CONTENTS}

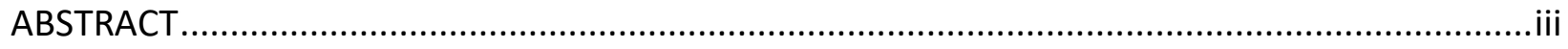

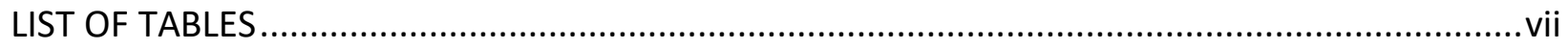

LIST OF FIGURES ................................................................................................................ vii

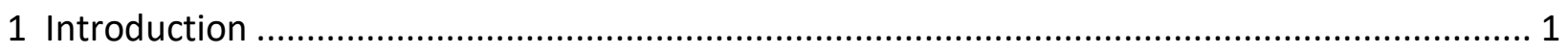

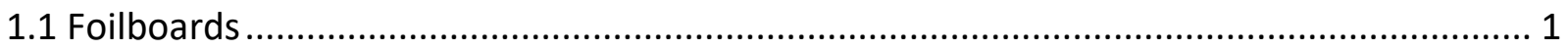

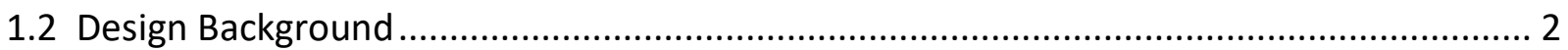

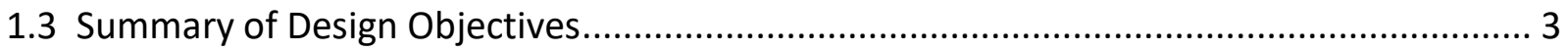

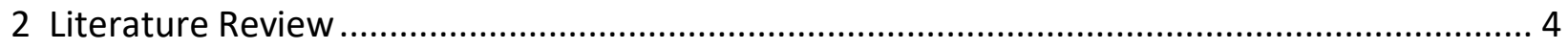

2.1 Overview of the Current Foilboard Market...................................................................... 4

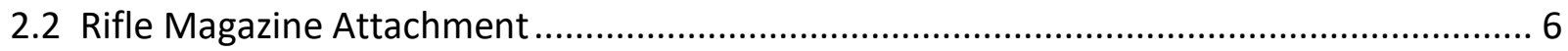

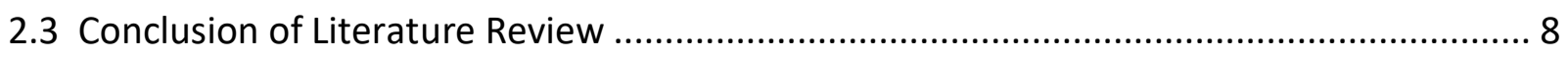

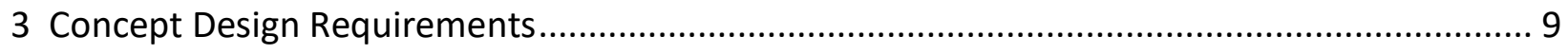

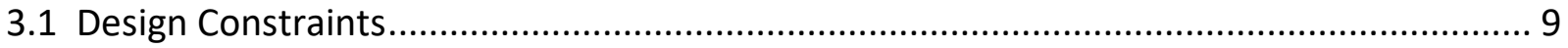

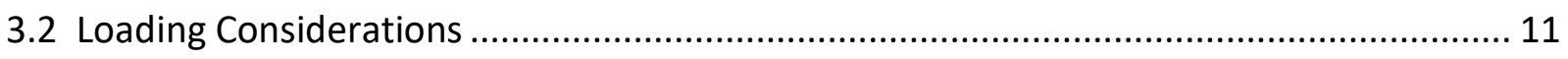

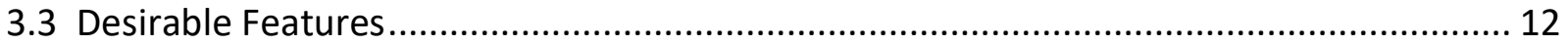

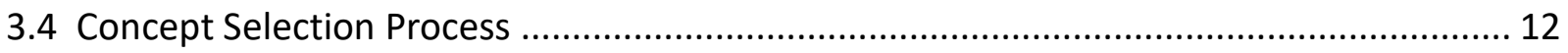

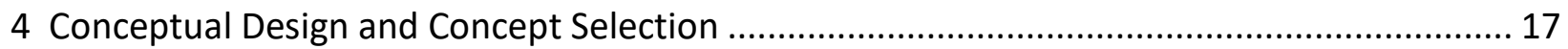

4.1 Design Concepts and Concept Generation .................................................................. 17

Concept 1 - Two Bolts from Below .............................................................................. 17

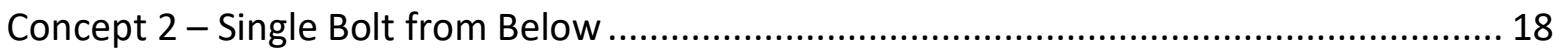

Concept 3 - Slide, with Single Fastening Bolt from Below................................................. 18

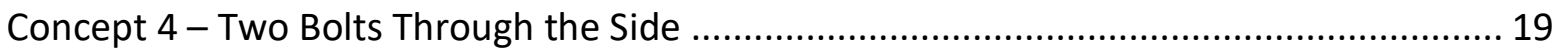

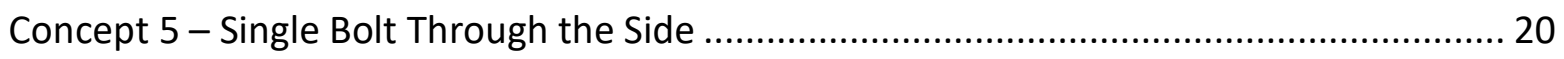

Concept 6 - Rear Clip with Single Bolt through Front ....................................................... 21

Concept 7 - Magazine Inspired Sliding Dovetail ................................................................... 21 


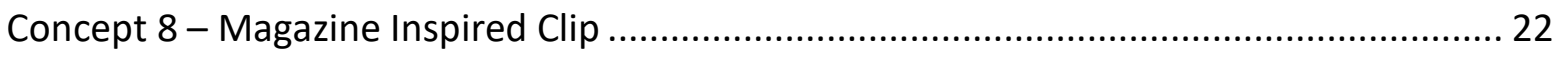

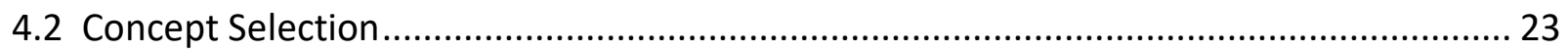

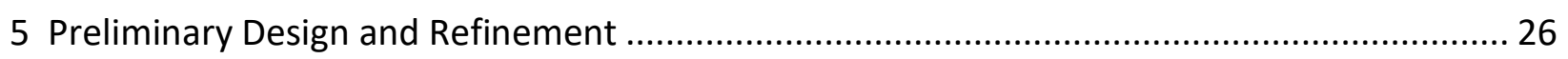

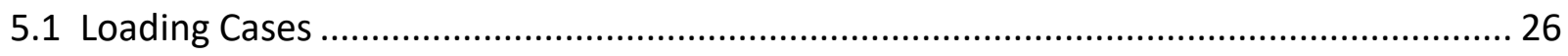

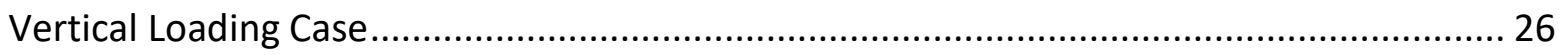

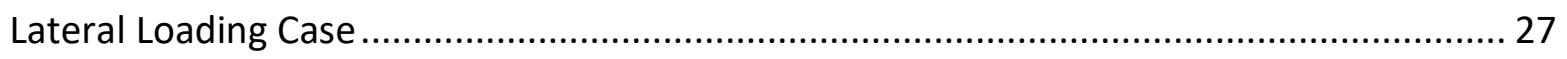

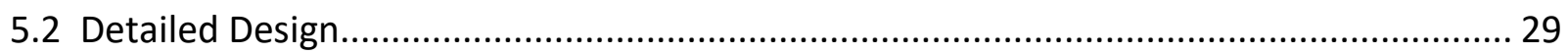

6 Presentation, Analysis and Discussion of Analytical Data .............................................. 34

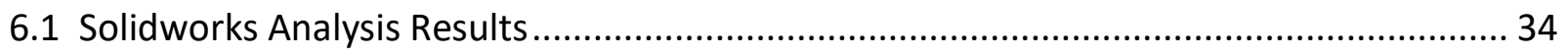

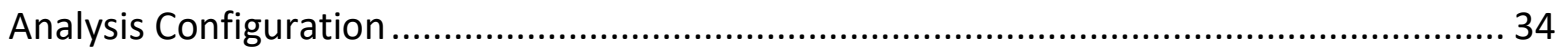

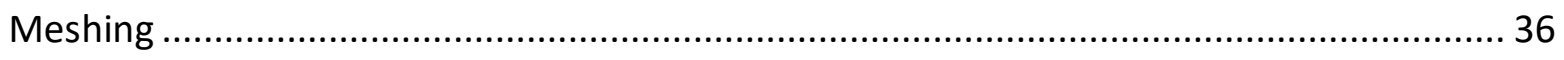

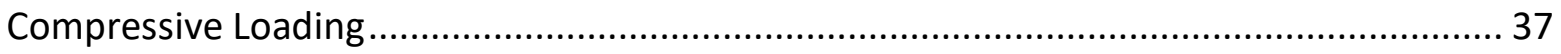

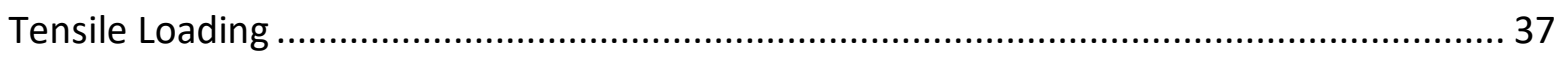

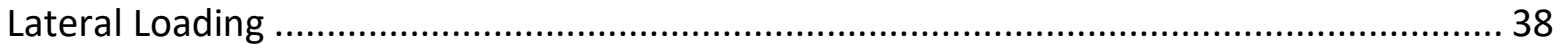

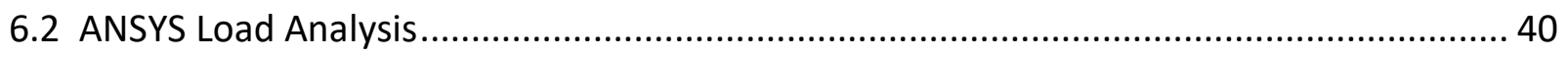

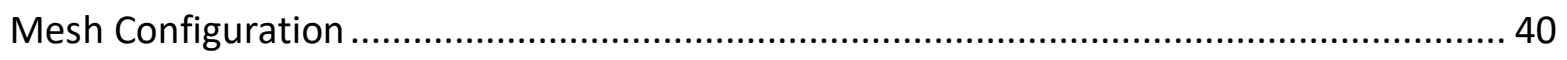

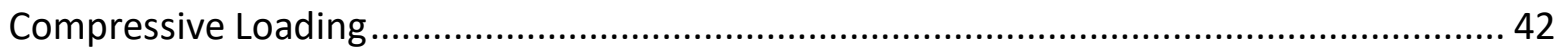

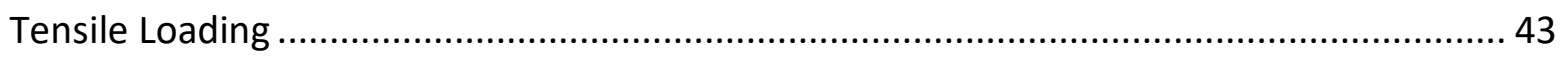

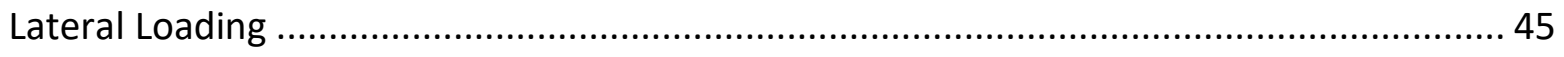

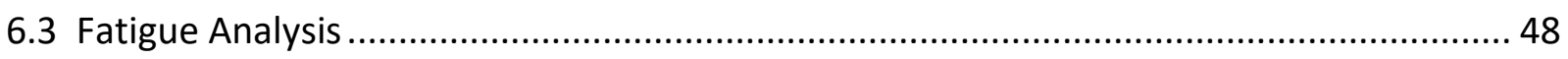

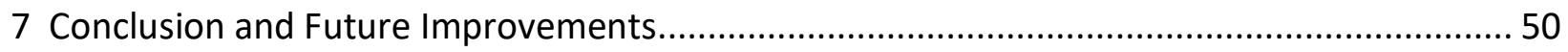

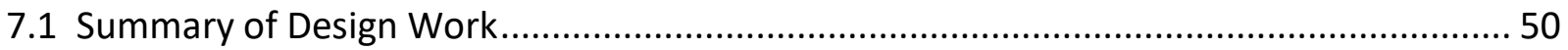

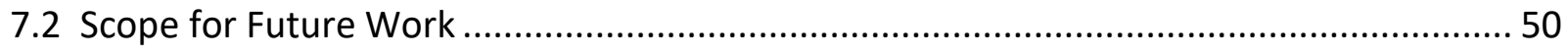

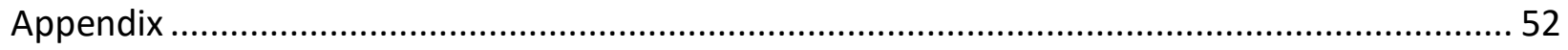

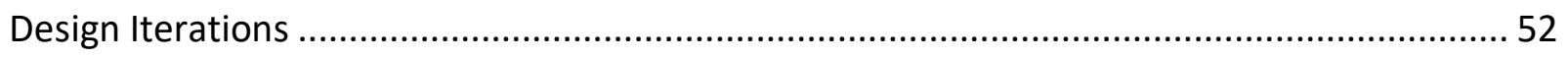




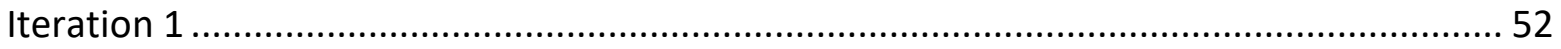

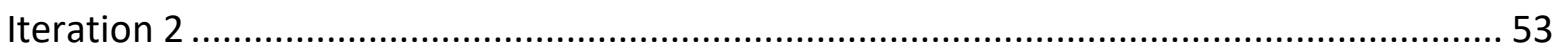

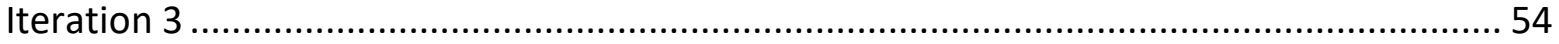

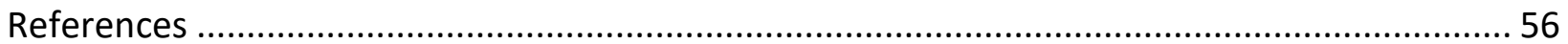




\section{LIST OF TABLES}

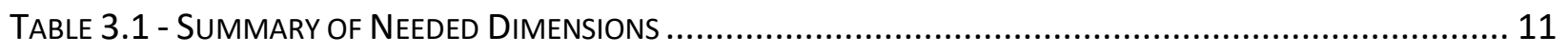

Table 3.2 - List of Metrics And The Rationale Behind SCOReS .................................................. 13

TABLE 3.3 - PAIRWISE COMPARISON Of DeSIGN METRICS ........................................................... 16

TABle 4.1 - Design Metrics Weighting Per ConCEPT ................................................................ 23

TABle 4.2 - Design Metrics Weighting Per Concept (CONT'D) ................................................... 24

TAble 5.1 - MaX AlLowable LoadS of CRItical CASES ............................................................... 28

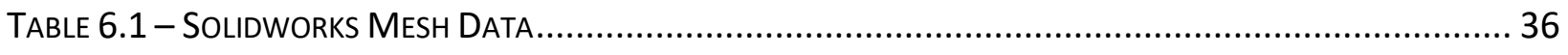

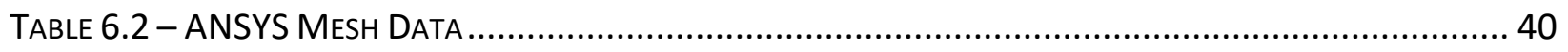

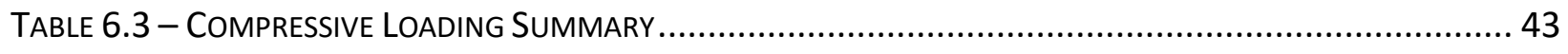

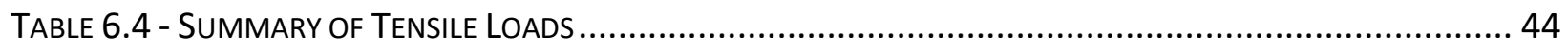

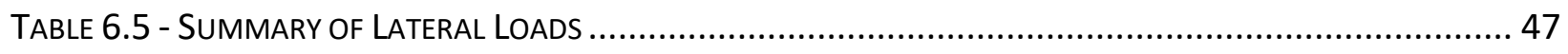

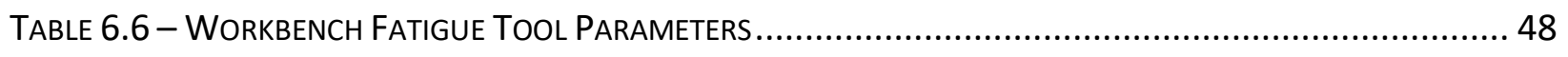

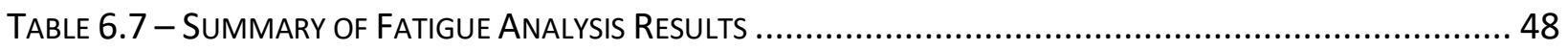




\section{LIST OF FIGURES}

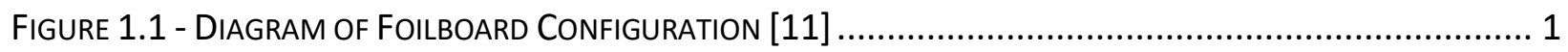

FigURE 2.1 - QUICK RELEASE COLLAR by LIQUID fORCE KITES [2] .................................................. 4

FigURE 2.2 - QUICK FLIGHT SYSTEM BY NOIR MATTER [3] .......................................................... 5

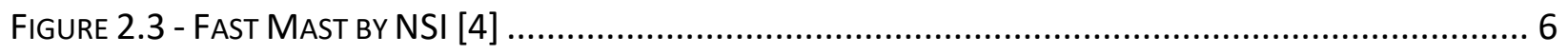

Figure 2.4 - Diagram of AK47 Magazine Attachment MeChanism [6] ....................................... 7

Figure 2.5 - Diagram of M16 Magazine Attachment MeChanism [7] ......................................... 8

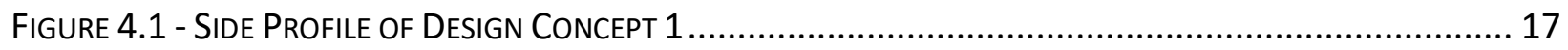

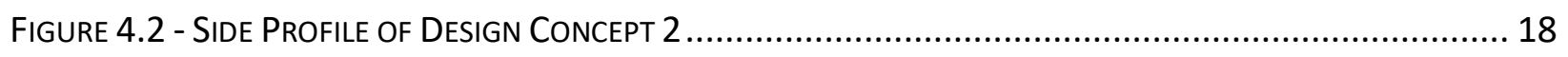

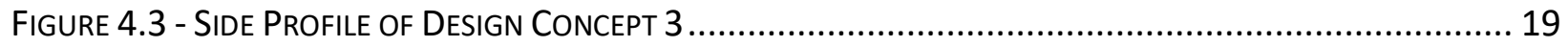

Figure 4.4 - Front AND Side ProfileS Of DeSIGn ConCEPT 4 .......................................................... 20

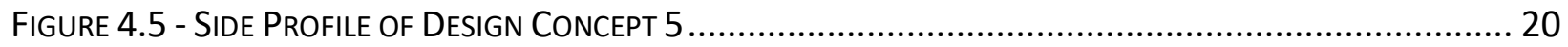

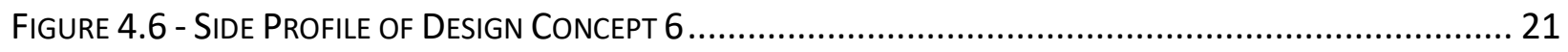

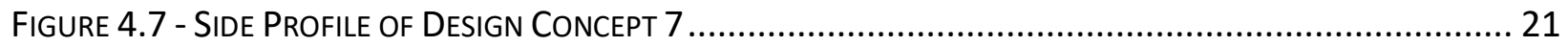

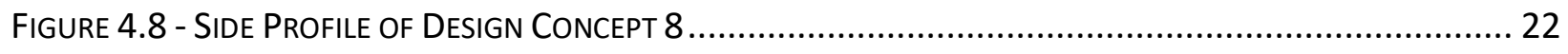

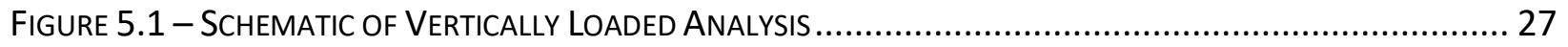

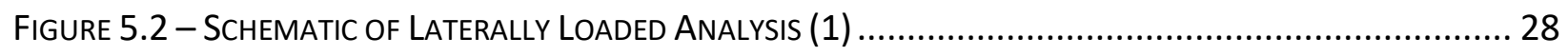

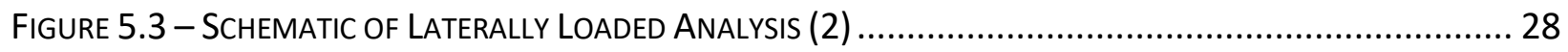

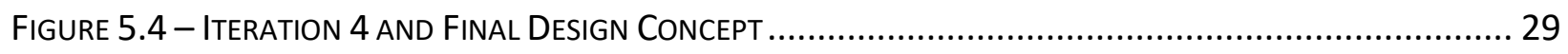

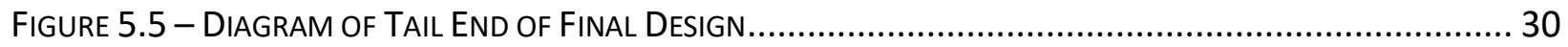

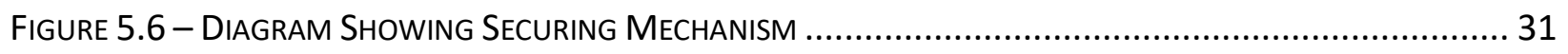

Figure 5.7 - OVerview of Final Attachment MeChanism DeSign ............................................... 32

Figure 5.8 - Diagram Showing Mechanism In Both Detached and Attached Positions .................... 33

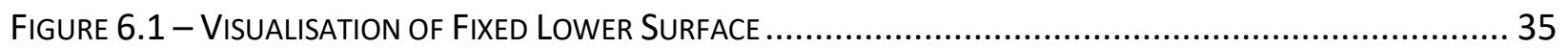

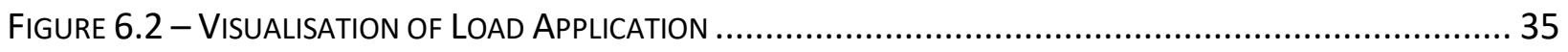

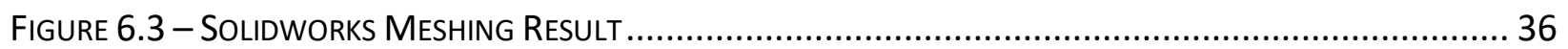


FiguRE 6.4 - SOLIDWORKS StRESS DISTRIBUTION OF COMPRESSIVE LOADING........................................ 37

FIgURE 6.5 - SolidWORKS STRESS DISTRIBUTION OF TENSILE LOADING ........................................... 38

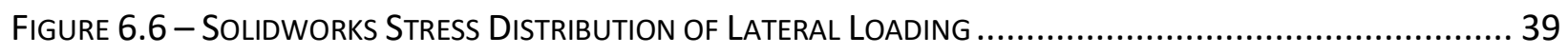

Figure 6.7 - Alternate Angle of Figure 6.6 Showing Rear Bolt Hole ........................................ 39

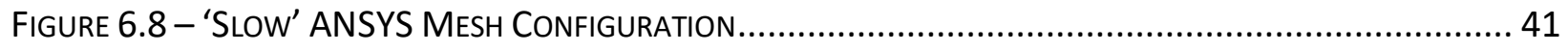

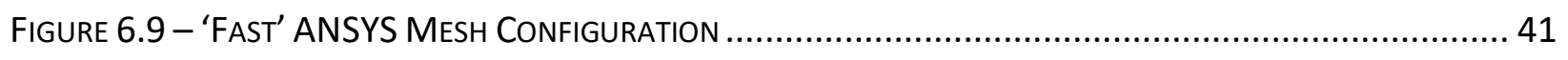

FIGURE 6.10 - ANSYS STRESS DISTRIBUTION OF COMPRESSIVE LOADING ........................................... 42

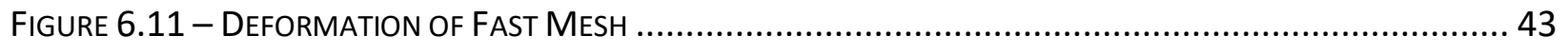

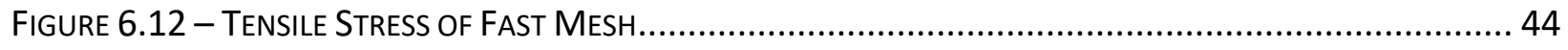

FiguRE 6.13 - TENSILE DEFORMATION Of FAST MESH ............................................................. 45

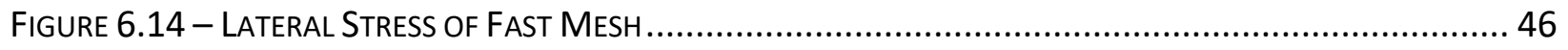

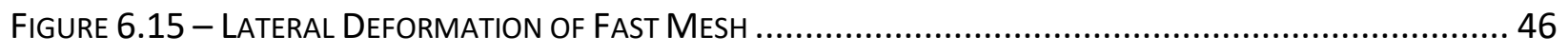

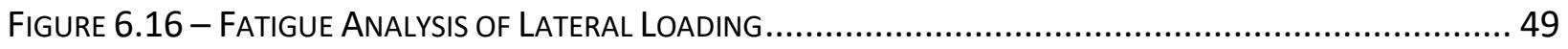




\section{Introduction}

\subsection{Foilboards}

A foilboard, or hydrofoil board, is a surfboard that has a hydrofoil attached to its bottom, allowing it to lift out of the water at higher speeds. Foilboards are generally unaffected by choppy or rough water conditions and are more versatile than traditional kiteboards. [1] They consist of a typical surfboard with mounting holes on its bottom, a vertical mast, and a fuselage which runs under the water, onto which both a front wing, and a stabiliser wing are attached. This configuration is shown below in Figure 1.1. The board attaches to the mounting plate, usually with four long bolts.

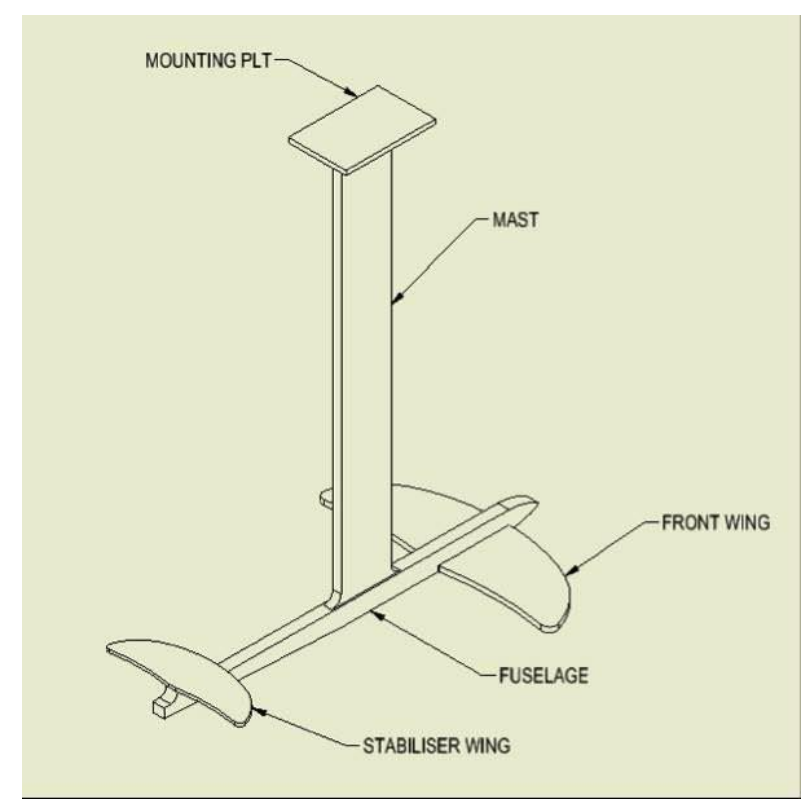

FIGURE 1.1 - DIAGRAM OF FOILBOARD Configuration [11]

Considering the configuration in Figure 1.1, the long bolts used to attach the mast, fuselage and board together result in a relatively long and tedious assembly process. Threading all the long bolts without power tools can take a few minutes, which makes quick assembly and disassembly difficult. As such, a quick release and detach mechanism of the mast from the fuselage would 
greatly improve the user experience, and serve as a unique selling point, allowing the design to stand out more effectively in the market.

\subsection{Design Background}

The first major constraint of designing such a mechanism is to ensure compatibility with the already existing Triton foil design. This design has already been analysed, built, and tested, all the dimensions are known, and CAD files are readily available. It is thus unnecessary to research and consider compatibility with market standards as all these parameters have been considered in the Triton design. Addionally, the Triton design is to be modified to incorporate a new Sichel mono-wing design. Again, considering Figure 1.1, the Sichel design replaces the fuselage, front wing and stabiliser wing with one single large wing attached directly to the bottom of the mast. The quick attach mechanism will serve as the interface between this mono-wing and the already existing Triton mast and mounting plate designs.

Using the Triton design as a base provides a starting point for apparatus sizing and load bearing calculations. It additionally provides a reference for determining the physical shape of the attachment to ensure the design is visually appealing. Thus, the following dimensions of the Triton design need to be considered when designing the quick release apparatus:

- Mast length of $850 \mathrm{~mm}$

- Mast chord of $109 \mathrm{~mm}$

- $\quad$ Mast weight of $1.4 \mathrm{~kg}$

- Fuselage and mounting plate hole spacing of $60 \mathrm{~mm}$, with $8 \mathrm{~mm}$ diameter

The second major constraint of this design is it must be lightweight. One of the major concerns of the Triton design is designing a foil that is significantly lighter than other options on the market. 


\subsection{Summary of Design Objectives}

The attachment mechanism must satisfy the following primary objectives:

1. The user must be able to assemble it with their hands only. No other tools should be required.

2. It must be lightweight.

3. It must be able to bear the same compressive, tensile, and bending loads during operation that bolt mounting methods can bear. It must also be equally or more fatigue resistant.

4. It must be hydrodynamic, i.e. it must not cause vibrations or any other fluid-based disturbances.

This design also has many secondary goals that are related to the production and implementation of the attachment mechanism:

1. It must be easy and inexpensive to manufacture.

2. It must look sleek and elegant. Looks are a distinctive selling point in the hydrofoil board industry.

3. It must be easy to clean of sand and other debris. 


\section{Literature Review}

\subsection{Overview of the Current Foilboard Market}

There are relatively few foilboards in the current market that are geared for quick assembly and disassembly. The designs that do exist allow the quick removal and attachment of the mast from the board; however, this project is interested in designing a quick attachment method of the mast from the lower fuselage or wing. Nevertheless, inspiration can still be drawn from those on the market.

One good example of a quick release mechanism is sold by Liquid Force Kites, called the Quick Release Collar, shown in Figure 2.1. This design features a slide and screw mechanism. The mast slides into a bracket at an angle, then rotates flat, and is secured with a single bolt at the rear [2]. The logic of this design is that instead of unscrewing several long screws, only one small screw is needed. The rear screw bears the longitudinal loads, and this screw works along with the physical contact between the two mounting surfaces to bear any pitching moments. This design is very simple and quick to install and can be machined out of aluminium like many other standard foilboard components.

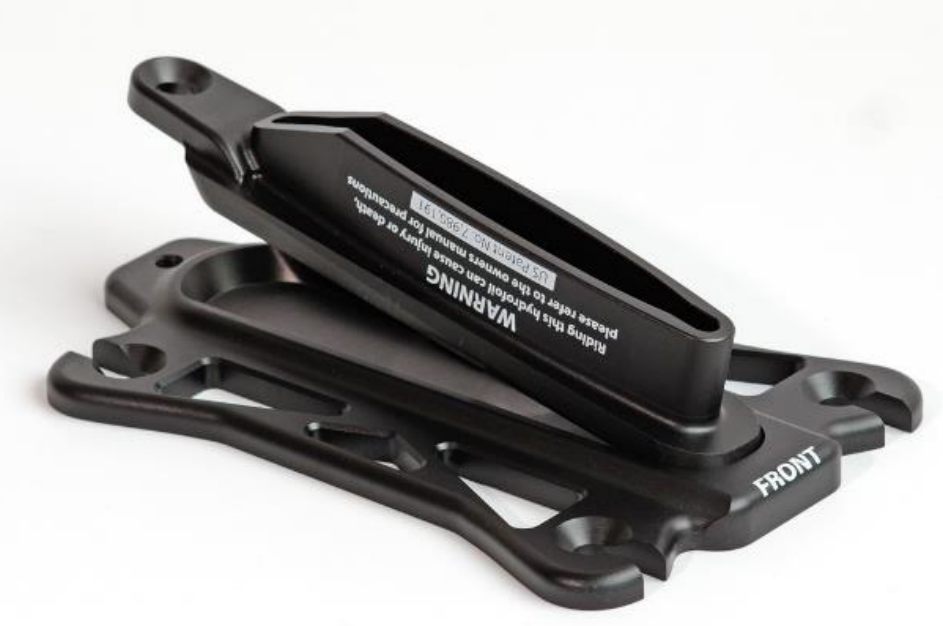

Figure 2.1 - QUick ReleASe Collar by LiQuid fORCE Kites [2] 


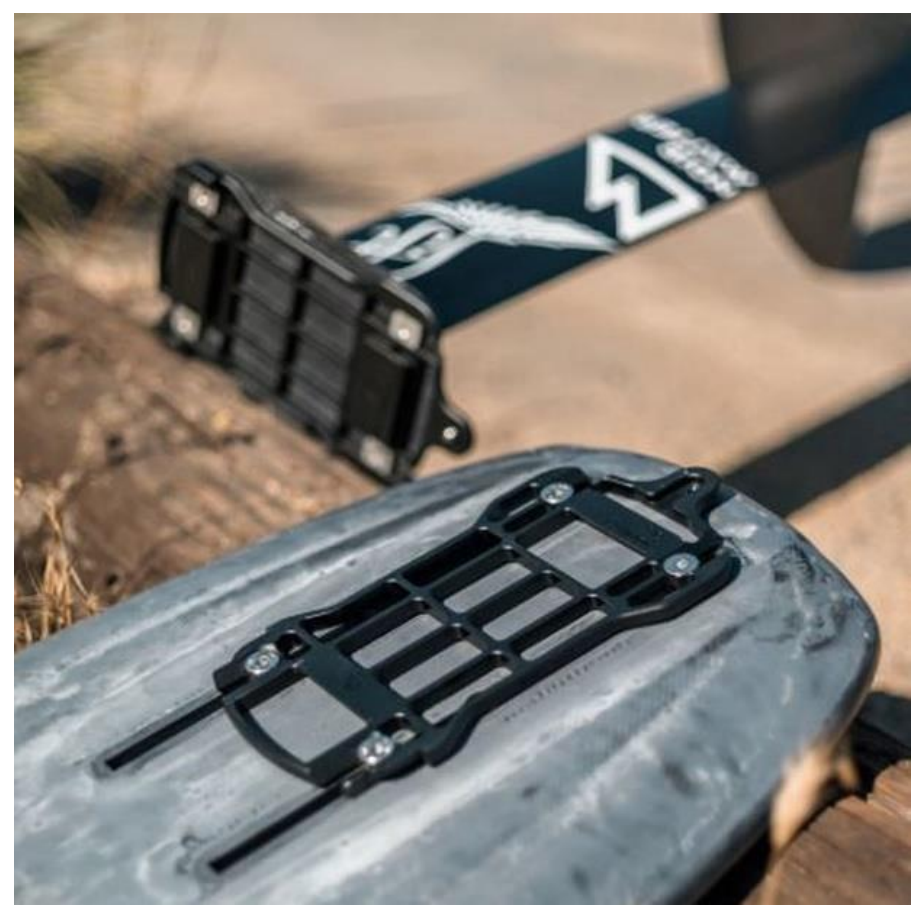

Figure 2.2 - QUick Flight SyStem by Noir MATter [3]

Another design, the Quick Flight System produced by Noir Matter, shown in Figure 2.2, features a slide and screw attachment method. This design has a stainless-steel bracket, four integrated tracks and an integrated thumbscrew for attachment. A thumbscrew is even more convenient than the previously mentioned QR Collar design, as Noir Matter claims that it only takes 10 seconds to assemble and disassemble a foil [3]. One immediately evident disadvantage with this design is the fact that it's constructed out of milled stainless steel and aluminium, which gives it a total mass of $450 \mathrm{~g}$. Noir Matter claims describes this mechanism as lightweight, however it can be lightened significantly by using all aluminium.

The third concept considered is the Fast Mast Hydrofoil Quick Release, by North Shore Inc, shown in Figure 2.3 overleaf. This design does not use a slide mechanism, but instead uses two stainless steel push pins to secure the mast to the upper board. This design is relatively simple and is comprised of two plate collars that are pressed together and pinned. [4] Like the Quick Flight System mentioned previously, the biggest concern with this design is its weight, at $454 \mathrm{~g}$, or one 
pound. There is clearly room in the market for a style of quick release mechanism that is significantly more lightweight than those researched.

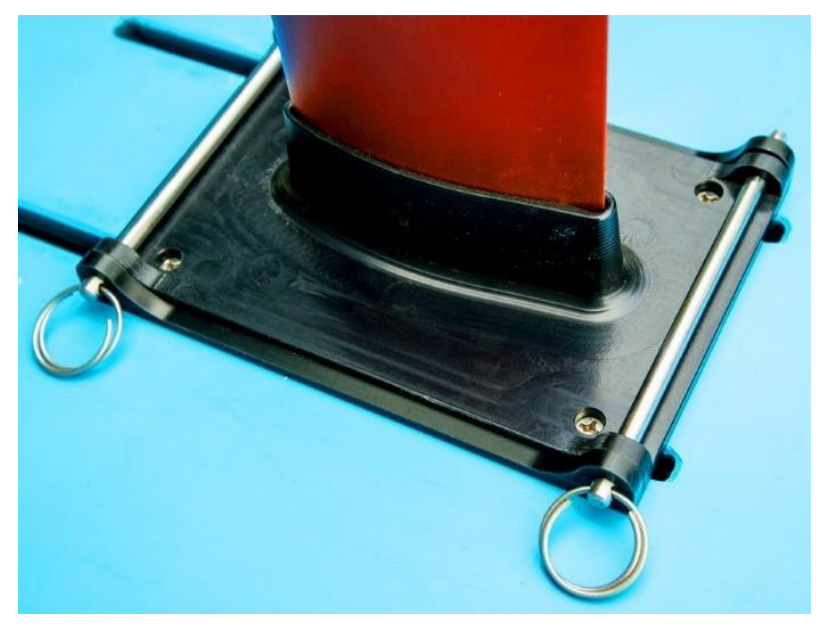

FIGURE 2.3 - FAST MAST BY NSI [4]

\subsection{Rifle Magazine Attachment}

A good source of inspiration for sturdy attachment mechanisms is the world of rifles. Assault rifle magazines are attached to the body of the guns using a variety of mechanisms, but most commonly are hook and clip attachments, or slide and click attachments.

The AK47 rifle features a good example of a hook and clip attachment method. Seen in Figure 2.4 overleaf, this design has a hook at the front end of the magazine that attaches onto the main body of the gun via a small metal tooth, marked 43. The magazine is then swung backwards around that point until it interfaces with a catch at the rear, marked 45. This catch features a series of torsion springs which keep the rear of the magazine in place, tensioned against the main body of the rifle. Detachment and attachment is easy, with a simple thumb button needed to release the magazine. This design at its core is similar conceptually to the QR Collar mentioned in the previous section, the difference being is there is no screw required, and the system does not require any tools to assemble. 


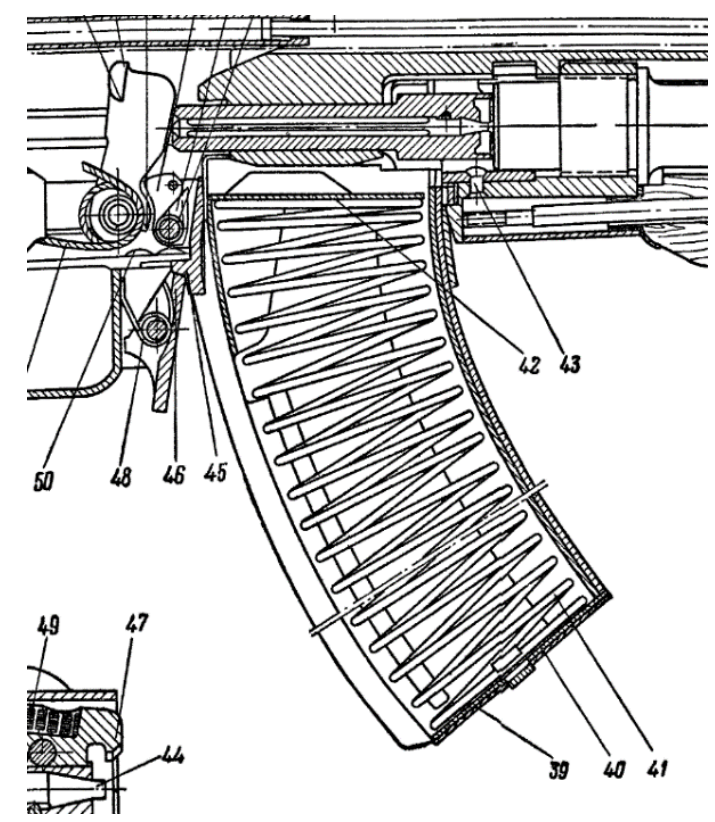

Figure 2.4 - Diagram of AK47 Magazine Attachiment Mechanism [6]

Another attachment design to consider is that of a sliding mechanism, as seen in the M16, seen in Figure 2.5 overleaf. This mechanism involves the magazine sliding vertically into the lower receiver of the rifle, and it is fastened in place by means of a spring tensioned catch. As the magazine ascends into the receiver, it pushes a spring lock out of the way, until it has entered sufficiently far enough that the spring lock extends into a notch, labelled 56 in the figure, in the magazine. The spring pushes the magazine into the lower receiver such that frictional forces keep it fixed in place. To remove the magazine, a simple push button is used which pushes the spring out of the locking notch. A design like this could also be used in a foilboard, however some additional reinforcement may be required, in the form of using a sliding dovetail joint which clicks into place. 


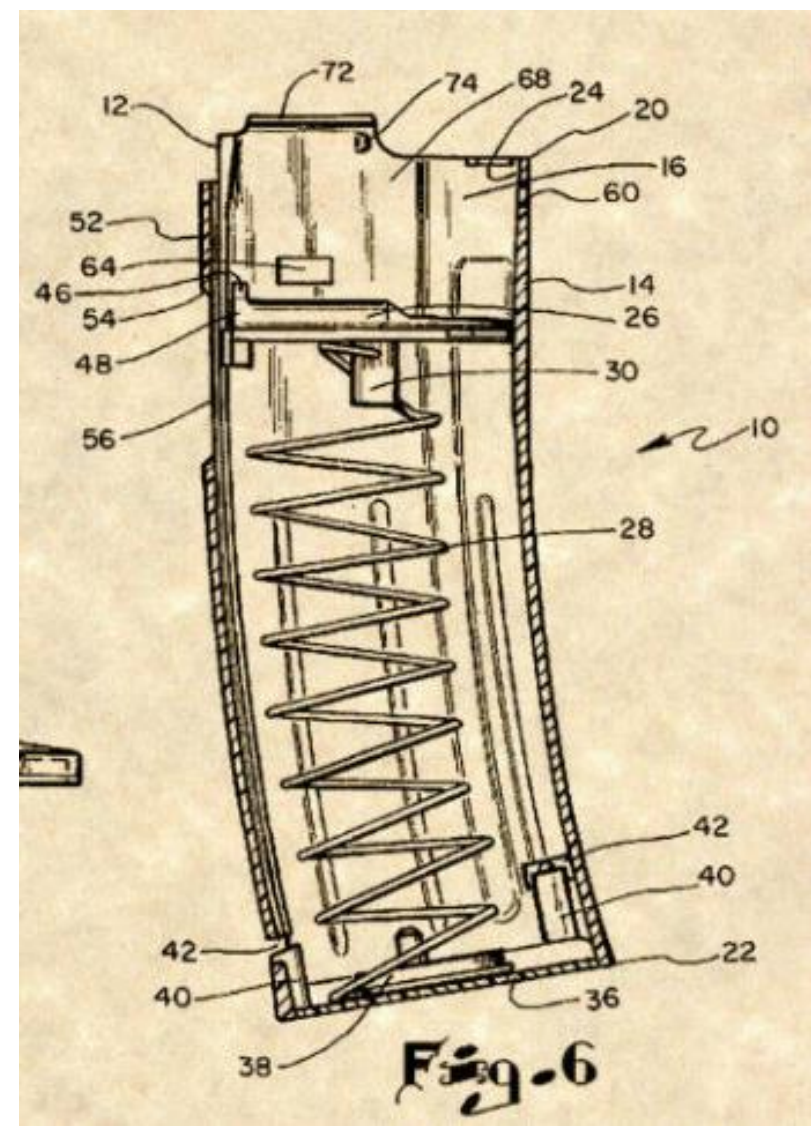

Figure 2.5 - Diagram of M16 Magazine Attachment Mechanism

[7]

\subsection{Conclusion of Literature Review}

This literature review explored both the options currently on the market regarding existing foilboard quick release and attach mechanisms, as well as rifle attachment mechanisms. The slide and screw mechanism seen in the foilboard market will be considered for conceptual designs. The simple pushpin concept will be more difficult to execute as the Sichel wing design isn't a flat board surface, where long pushpins are easy to install. The rifle sliding dovetail mechanism, as well as the hook and clip mechanism will both be considered, as these are very promising for use in foilboards. 


\section{Concept Design Requirements}

This design effort began with a series of design requirements for both conceptualising and selecting the most suitable concepts. These requirements are divided into design constraints, loading and force requirements, and desirable features.

\subsection{Design Constraints}

Concepts generated must consider the following design constraints:

- Design must be compatible with the already existing extruded and CNC machined Triton mast designs, and the new Sichel wing design.

- The surface interfacing with the mast must match the Triton foil shape for visual continuity

- Must be mountable to the existing $8 \mathrm{~mm}$ mast holes spaced $60 \mathrm{~mm}$ apart

- The surface interfacing with the wing must either fit inside of or be installed onto the $94 \times 162 \mathrm{~mm}$ flat central portion of the wing.

- Design will be manufactured using Al 6061-T6. This alloy has already been used in production of the Triton fuselage, mast, and mast base. This will reduce cost and simplify manufacturing.

- Design should use as few CNC steps and tool changes as possible. The Triton design involved an experimental CNC machined mast which was expensive and costly to make, thus CNC work must be minimised.

- Design must be sufficiently fatigue resistant. The design, if not using standard bolts, must be able to survive the same number of loading cycles as $8 \mathrm{~mm}$ bolts. This can be quantified in terms of the number of points of contact, surface area of those contact 
points, and whether loads experienced are oriented such that said contact points are providing the best support.

- Design must be water resistant. All materials must be resistant to water or coated to provide water resistance.

- Design must be lightweight. A maximum design weight of $300 \mathrm{~g}$ for all components was defined given research outlined in the previous literature review section.

- Design must be quick to install. An installation time under 10 seconds was defined given market research of other quick attach mechanisms.

- Design must be hydrodynamic. It must feature smooth curves to reduce hydrodynamic shocks and vibrations. 


\subsection{Loading Considerations}

The typical loads experienced during foilboard use are needed to set the loading conditions for design simulation analysising. To determine these values, parameters such as average rider weight and average board size are needed. From a survey conducted by D. Heyden on a group of 29 members of the World Surfing League [5], the average weight of a surfboard rider was to be $76.66 \mathrm{~kg}$. The application point of this weight load can be calculated from a few datapoints. From a design article written by the company FoilMount [6], the optimal mast mounting plate position should be affixed between 10-15" from the rear edge of the board. Given that the mast mounting hole spacing of the Triton design is $125 \mathrm{~mm}$, this put the mast $380 \mathrm{~mm}$ from the rear edge of the board when taking the average of the place fastening distance. Considering surfboard size, the Triton design is intended for use with any surfboard, as such, an average must be used for board size. From Surfing Waves, a surfboard advice forum run by a surf shop, given an average weight of $76.66 \mathrm{~kg}$, the recommended board length is $1.98 \mathrm{~m}$, with a width of $0.492 \mathrm{~m}$ [7]. This information is summarised in Table 3.1.

TABle 3.1 - Summary of Needed Dimensions

\begin{tabular}{|c|c|c|c|}
\hline Width of Board & $\mathbf{4 9 . 2 \mathrm { cm }}$ & Mast Length & $\mathbf{8 5 \mathrm { cm }}$ \\
\hline Length of Board & $198 \mathrm{~cm}$ & Mast Chord & $10.9 \mathrm{~cm}$ \\
\hline Weight of Rider & $76.66 \mathrm{~kg}$ & Mast Weight & $1.4 \mathrm{~kg}$ \\
\hline Mast Mount Hole Spacing & $125 \mathrm{~mm}$ & & \\
\hline
\end{tabular}




\subsection{Desirable Features}

There are several features which are desirable, but are not necessarily needed to meet the main design constraints:

- Design should be assembled without any tools. Tool-less assembly both reduces the apparatus needed to be unpacked and repacked with each assembly and disassembly of the design and makes the process more convenient for the user.

- Design should be secured either with one bolt, short bolts, or no bolts. These three conditions reduce or remove the lengthy screwing and unscrewing processes from assembly.

- Design must be aesthetically pleasing. While difficult to quantify, looks are an important selling point in the surfing hydrofoil market.

\subsection{Concept Selection Process}

During the concept design and selection process, designs must be compared to each other via a framework to determine which concepts are the most promising, or suitable for further analysis. The constraints mentioned previously in this section have been consolidated into a table of metrics, which will be compared and weighted to each other through a pairwise comparison process. This method allows the worded objectives to be transformed into numerical targets. The following metrics were considered:

- Fatigue Resistance

- Time to Install

- Manufacturing Cost

- Weight
- Manufacturing Time

- Strength

- Looks/Elegance

- Hydrodynamics 
Each design was compared using the above metrics, with each design given a score from 1 to 5 under each metric. The rationale behind the scores of each of the above metrics is outlined in Table 3.2.

TABle 3.2 - List of Metrics and The Rationale Behind SCOReS

\begin{tabular}{|c|c|c|c|c|c|}
\hline Metric & 1 & 2 & 3 & 4 & 5 \\
\hline $\begin{array}{l}\text { Fatigue } \\
\text { Resistance }\end{array}$ & $\begin{array}{l}\text { Small surface } \\
\text { areas in contact } \\
\text { along minor load } \\
\text { axis, secured with } \\
\text { clips, springs, or } \\
\text { one bolt loaded } \\
\text { under tension }\end{array}$ & $\begin{array}{l}\text { Small surface } \\
\text { areas in contact } \\
\text { along major load } \\
\text { axis, secured with } \\
\text { clips, springs, or } \\
\text { one bolt loaded } \\
\text { under tension }\end{array}$ & $\begin{array}{l}\text { Large surface } \\
\text { areas in contact } \\
\text { along major load } \\
\text { axis, secured with } \\
\text { clips, springs, or } \\
\text { one bolt loaded } \\
\text { under tension }\end{array}$ & $\begin{array}{l}\text { Large surface } \\
\text { areas in contact } \\
\text { along major load } \\
\text { axis, secured with } \\
\text { captive clips, } \\
\text { springs, or } \\
\text { multiple bolts } \\
\text { loaded under } \\
\text { tension }\end{array}$ & $\begin{array}{l}\text { Large surface } \\
\text { areas in contact } \\
\text { along major load } \\
\text { axis, secured with } \\
\text { captive clips, } \\
\text { springs, or bolts } \\
\text { which are loaded } \\
\text { under shear }\end{array}$ \\
\hline $\begin{array}{l}\text { Manufacturing } \\
\text { Time }\end{array}$ & $\begin{array}{l}\text { Requires } \\
\text { extensive CNC } \\
\text { machining with } \\
\text { many tool } \\
\text { changes, requires } \\
\text { CNC machined } \\
\text { mast }\end{array}$ & $\begin{array}{l}\text { Requires } \\
\text { extensive CNC } \\
\text { machining with } \\
\text { few tool changes, } \\
\text { requires CNC } \\
\text { machined mast }\end{array}$ & $\begin{array}{l}\text { Requires few CNC } \\
\text { machining } \\
\text { operations with } \\
\text { few tool changes, } \\
\text { can use extruded } \\
\text { mast }\end{array}$ & $\begin{array}{l}\text { Requires no CNC } \\
\text { machining, } \\
\text { multiple boring } \\
\text { operations, can } \\
\text { use extruded } \\
\text { mast }\end{array}$ & $\begin{array}{l}\text { Requires no CNC } \\
\text { machining, only } \\
\text { single operations } \\
\text { for bolt holes, } \\
\text { can use extruded } \\
\text { mast }\end{array}$ \\
\hline Time to Install & $\begin{array}{l}\text { Takes more than } \\
10 \text { seconds to } \\
\text { install }\end{array}$ & $\begin{array}{l}\text { Takes between 8- } \\
10 \text { seconds to } \\
\text { install }\end{array}$ & $\begin{array}{l}\text { Takes } 5 \text { to } 8 \\
\text { seconds to install }\end{array}$ & $\begin{array}{l}\text { Takes } 3 \text { to } 5 \\
\text { seconds to install }\end{array}$ & $\begin{array}{l}\text { Takes less than } 3 \\
\text { seconds to install }\end{array}$ \\
\hline Strength & $\begin{array}{l}\text { No significant } \\
\text { contact area } \\
\text { between parts, } \\
\text { single fastening } \\
\text { component with } \\
\text { single point of } \\
\text { contact }\end{array}$ & $\begin{array}{l}\text { Parts in loose fit } \\
\text { or friction fit with } \\
\text { small surface } \\
\text { area, single } \\
\text { fastening } \\
\text { component with } \\
\text { single point of } \\
\text { contact }\end{array}$ & $\begin{array}{l}\text { Parts in friction } \\
\text { fit, single } \\
\text { fastening } \\
\text { component with } \\
\text { single point of } \\
\text { contact }\end{array}$ & $\begin{array}{l}\text { Parts in friction } \\
\text { fit, multiple } \\
\text { fastening } \\
\text { components with } \\
\text { single point of } \\
\text { contact }\end{array}$ & $\begin{array}{l}\text { Parts in friction, } \\
\text { multiple } \\
\text { fastening } \\
\text { components with } \\
\text { multiple points of } \\
\text { contact }\end{array}$ \\
\hline
\end{tabular}


Table 3.2 - List of Metrics and The Rationale Behind Scores (Continued)

\begin{tabular}{|c|c|c|c|c|c|}
\hline Metric & 1 & 2 & 3 & 4 & 5 \\
\hline $\begin{array}{l}\text { Manufacturing } \\
\text { Cost }\end{array}$ & $\begin{array}{l}\text { Uses CNC } \\
\text { machined mast, } \\
\text { requires } \\
\text { extensive CNC } \\
\text { machining and/or } \\
\text { carbon fibre } \\
\text { moulding }\end{array}$ & $\begin{array}{l}\text { Uses CNC } \\
\text { machined mast, } \\
\text { CNC machining } \\
\text { needed for both } \\
\text { wing and mast } \\
\text { attachment } \\
\text { points }\end{array}$ & $\begin{array}{l}\text { Uses extruded } \\
\text { mast, CNC } \\
\text { machining } \\
\text { needed for both } \\
\text { wing and mast } \\
\text { attachment } \\
\text { points }\end{array}$ & $\begin{array}{l}\text { Uses extruded } \\
\text { mast, CNC } \\
\text { machining } \\
\text { needed for only } \\
\text { one attachment } \\
\text { component }\end{array}$ & $\begin{array}{l}\text { Uses extruded } \\
\text { mast, no CNC } \\
\text { machining } \\
\text { required }\end{array}$ \\
\hline Looks/Elegance & \multicolumn{5}{|c|}{$\begin{array}{l}\text { Purely subjective. Score assigned based on how concept looks, or how elegant the attachment } \\
\text { design is. }\end{array}$} \\
\hline Weight & $\begin{array}{l}\text { Design will be } \\
\text { over the } 300 \mathrm{~g} \\
\text { limit. }\end{array}$ & $\begin{array}{l}\text { Design is within } \\
5 \% \text { of } 300 \mathrm{~g} \text { limit. }\end{array}$ & $\begin{array}{l}\text { Design is }>10 \% \\
\text { under limit, two } \\
\text { long bolts used. }\end{array}$ & $\begin{array}{l}\text { Design is }>10 \% \\
\text { under limit, two } \\
\text { short bolts, or } \\
\text { one long bolt } \\
\text { used, or pre- } \\
\text { installed adapter } \\
\text { plates needed. }\end{array}$ & $\begin{array}{l}\text { Design is }>10 \% \\
\text { under limit, no } \\
\text { bolts used, no } \\
\text { adapter plates } \\
\text { needed. }\end{array}$ \\
\hline Hydrodynamics & $\begin{array}{l}\text { Part has a high } \\
\text { drag geometry } \\
\text { with fasteners or } \\
\text { bolts that require } \\
\text { holes drilled } \\
\text { laterally across } \\
\text { design }\end{array}$ & $\begin{array}{l}\text { Part has a high } \\
\text { drag geometry } \\
\text { with either no } \\
\text { holes, } \\
\text { countersunk } \\
\text { bolts, or flush } \\
\text { external } \\
\text { fasteners }\end{array}$ & $\begin{array}{l}\text { Part has smooth } \\
\text { curves with } \\
\text { fasteners or bolts } \\
\text { that require holes } \\
\text { drilled laterally } \\
\text { across design }\end{array}$ & $\begin{array}{l}\text { Part has smooth } \\
\text { curves with } \\
\text { countersunk bolts } \\
\text { or flush external } \\
\text { fasteners }\end{array}$ & $\begin{array}{l}\text { Part has smooth } \\
\text { curves with no } \\
\text { bored holes or } \\
\text { protrusions in the } \\
\text { fluid flow }\end{array}$ \\
\hline
\end{tabular}


The scores for each metric have been categorised as follows:

- Fatigue Resistance is rated by considering the surface areas in contact in the design, and the type, orientation and number of fasteners. Bolts for example are more resistant to loosening overtime than a simple friction fit. A large friction surface area distributes forces across a larger area and thus more cycles can be endured given a constant alternating load.

- Manufacturing Time is rated according to the intensity of CNC machining and material removal operations involved.

- Time to Install is rated purely on the estimated time of installation.

- Strength is a rating of the mating strength of the attachment design. This is related to contact surface area, tightness of part fits, and the number, type, and location of fasteners.

- Manufacturing Cost is rated according to the number of CNC steps and the time that those steps take. It also considers the CNC time needed to make moulds for carbon fibre or fibreglass.

- Looks/Elegance is rated purely subjectively.

- Weight is rated based on both the number of bolts, size or type of fasteners involved, as well as additional estimation based on reference to existing Triton parts.

- Hydrodynamics is rated based on the shape of the design, as well as any protrusions, divots, cavities or other disturbances which may cause turbulence during use.

Each of the above design metrics was then weighted against each other to determine which are the most significant goals a design must achieve. This weighting is shown overleaf in Table 3.3. This table is read by selecting a metric in the leftmost column and travelling across the row to the right. A value of 1 in a cell represents that the metric to the left is more significant to optimise for that the one above, while a value of 0 represents the opposite. 
Table 3.3 - Pairwise Comparison of Design Metrics

\begin{tabular}{|c|c|c|c|c|c|c|c|c|c|c|c|}
\hline Metrics & $\begin{array}{l}\text { Fatigue } \\
\text { Resistance }\end{array}$ & $\begin{array}{l}\text { Time to } \\
\text { Install }\end{array}$ & $\begin{array}{l}\text { Manufact- } \\
\text { uring Cost }\end{array}$ & Weight & $\begin{array}{l}\text { Manufact- } \\
\text { uring Time }\end{array}$ & Strength & $\begin{array}{l}\text { Looks/Ele- } \\
\text { gance }\end{array}$ & $\begin{array}{l}\text { Hydro- } \\
\text { dynamics }\end{array}$ & Tot & N.Tot & $\begin{array}{l}\text { Rel. } \\
\text { Weight }\end{array}$ \\
\hline $\begin{array}{l}\text { Fatigue } \\
\text { Resistance }\end{array}$ & $x$ & 1 & 1 & 0 & 1 & 0 & 1 & 1 & 5 & 11 & $18 \%$ \\
\hline $\begin{array}{l}\text { Time to } \\
\text { Install }\end{array}$ & 0 & $x$ & 1 & 0 & 1 & 0 & 1 & 1 & 4 & 9 & $14 \%$ \\
\hline $\begin{array}{l}\text { Manufact- } \\
\text { uring Cost }\end{array}$ & 0 & 0 & $x$ & 0 & 1 & 0 & 0 & 0 & 2 & 5 & $8 \%$ \\
\hline Weight & 1 & 1 & 1 & $x$ & 1 & 0 & 1 & 1 & 6 & 13 & $20 \%$ \\
\hline $\begin{array}{l}\text { Manufact- } \\
\text { uring Time }\end{array}$ & 0 & 0 & 0 & 0 & $x$ & 0 & 0 & 0 & 0 & 1 & $2 \%$ \\
\hline Strength & 1 & 1 & 1 & 1 & 1 & $x$ & 1 & 1 & 7 & 15 & $23 \%$ \\
\hline $\begin{array}{l}\text { Looks/Eleg- } \\
\text { ance }\end{array}$ & 0 & 0 & 0 & 0 & 1 & 0 & $x$ & 0 & 1 & 3 & $5 \%$ \\
\hline $\begin{array}{l}\text { Hydrodyn- } \\
\text { amics }\end{array}$ & 0 & 0 & 1 & 0 & 1 & 0 & 1 & $x$ & 3 & 7 & $11 \%$ \\
\hline Total & & & & & & & & & 28 & 64 & \\
\hline
\end{tabular}

From the results of this weighting, the metrics have been sorted as follows, from most to least significant:

1- Strength, weight of $23.44 \%$

2- Weight, weight of $20.31 \%$

3- Fatigue Resistance, weight of $17.19 \%$

4- Time to Install, weight of $14.06 \%$
5- Hydrodynamics, weight of $10.94 \%$

6- Manufacturing Cost, weight of $7.81 \%$

7- Looks/Elegance, weight of $4.69 \%$

8- Manufacturing Time, weight of $1.56 \%$

The percentages are calculated by summing the totals in each row, then doubling that total and adding 1. These totals are summed into a Normalised Total, which is then used to calculate percentages. The weighting results described are consistent with the objectives outlined in the introduction. Strength, weight, fatigue resistance, and install time are the most important metrics to optimise for, while manufacturing time and looks are nice to have features and not essential to design a well functioning part. 


\section{Conceptual Design and Concept Selection}

\subsection{Design Concepts and Concept Generation}

Given prior engineering knowledge and research obtained during the literature review, eight design concepts were generated.

\section{Concept 1 - Two Bolts from Below}

Concept 1 is the existing Triton design, a simplified version of which is shown in Figure 4.1. This was done to provide a baseline for comparison with alternative attachment designs. It uses two long M8 bolts to attach the mast to the fuselage. The Sichel wing features a raised platform on top that provides a flat surface for the connection interface.

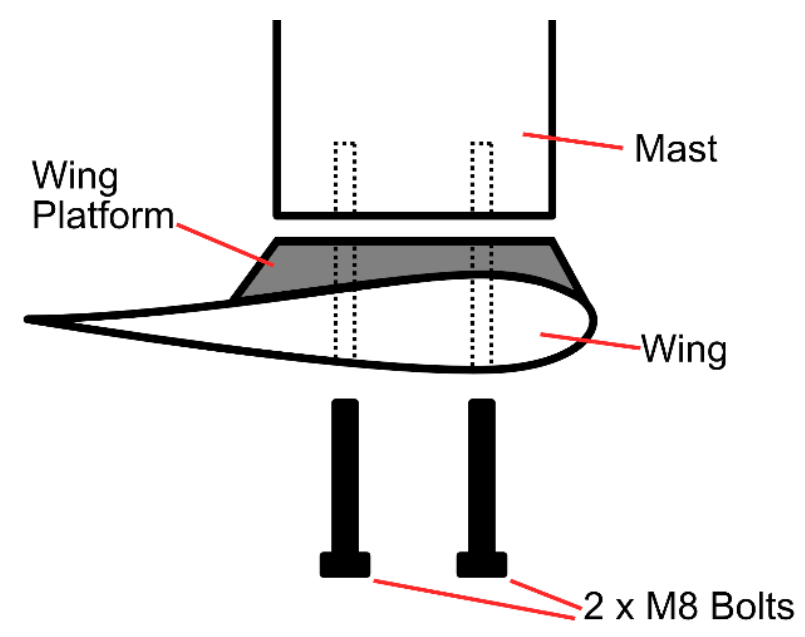

Figure 4.1 - Side Profile of Design ConCePt 1 


\section{Concept 2 - Single Bolt from Below}

This design is a simple variation of Concept 1 , featuring a single bolt instead of two, and is shown in Figure 4.2. One cause for concern during the Triton foil design process was that the bolts are rather heavy given their length and material. Thus, using one bolt would reduce the weight of the original design. Using a single bolt results in pitching moment forces being absorbed by the mast and wing platform in contact.

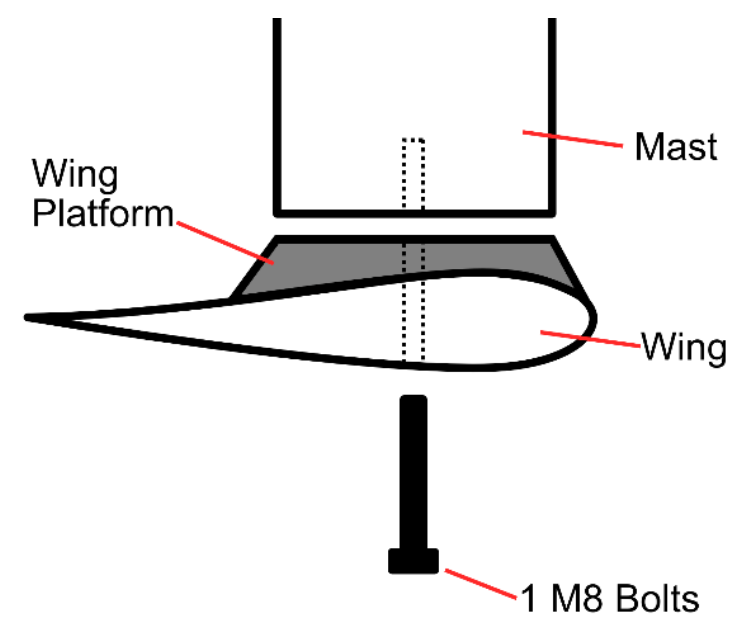

Figure 4.2 - Side Profile of Design Concept 2

Concept 3 - Slide, with Single Fastening Bolt from Below

Concept 3 is a modification of Concept 2, with the addition of a slide in attachment method. Rails are installed onto a bracket that is bolted to the bottom of the mast, which interfaces with receptacles mounted in the wing platform. This configuration is shown in Figure 4.3 overleaf. Since the vertical, lateral, and longitudinal forces will be absorbed by the physical sliding mechanism, the single bolt used to fasten the mast in place can be much shorter and of a smaller diameter, saving significant weight. 


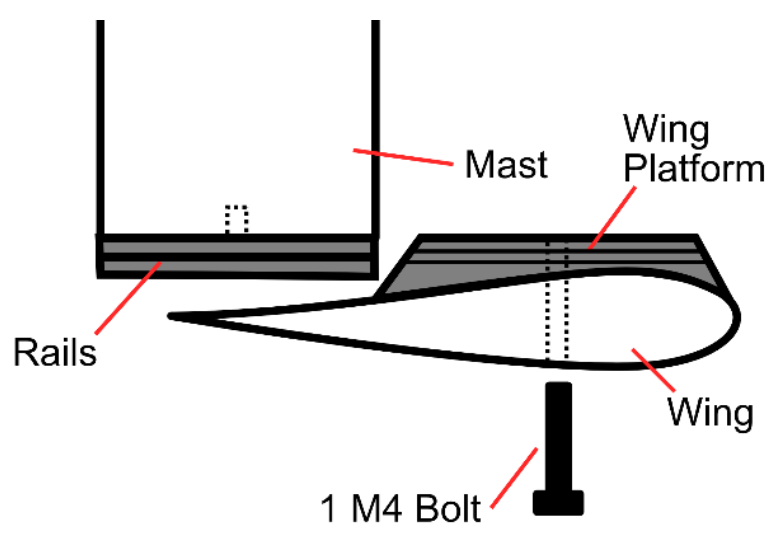

Figure 4.3 - Side Profile of Design ConCEPt 3

\section{Concept 4 - Two Bolts Through the Side}

Concept 4 explores a configuration suggested during the original Triton foil design process which uses two bolts through the side of the mast-wing interface. Shown in the combined Figure 4.4 overleaf, this concept has the mast slide down into a socket made in the wing platform, and two bolts are used to fasten the mast in place. The bolts are aligned longitudinally across the width of the mast. Due to the short length of the bolts required, two bolts would be significantly lighter in this configuration than the two bolts of Concept 1, and using two bolts in this manner allows weight savings without relying on face contact to absorb pitching loads like in Concept 2. A major disadvantage of this design would be that the inexpensive extruded aluminium mast used in the Triton would need to be replaced with a more expensive CNC machined mast to support the mounting holes. 

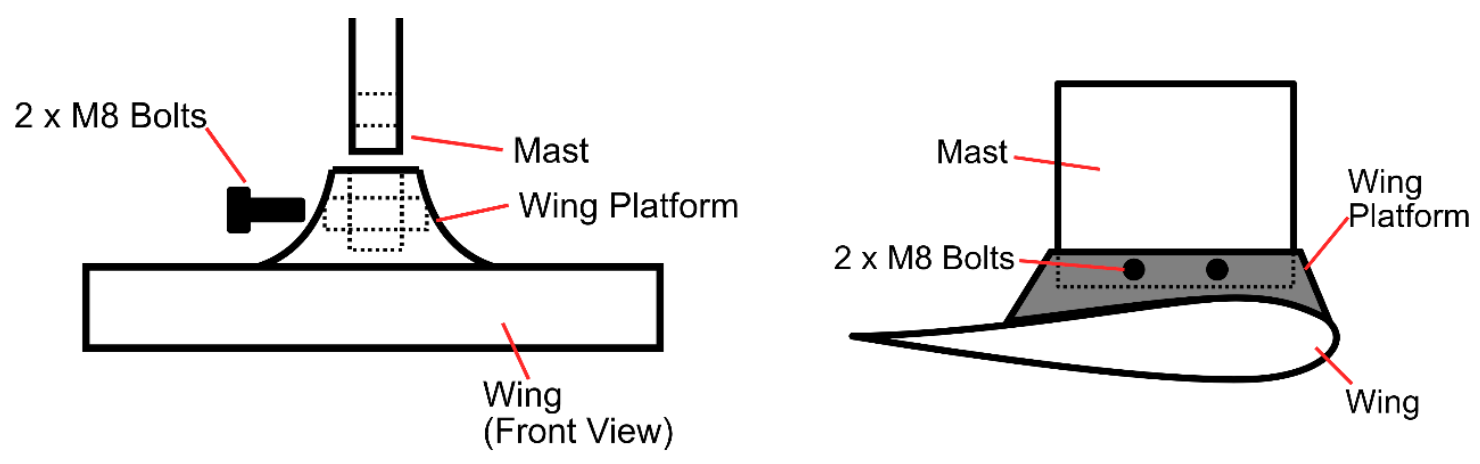

Figure 4.4 - Front and Side Profiles of Design Concept 4

Concept 5 - Single Bolt Through the Side

This concept is a variation of Concept 4, following a similar idea to Concept 2, and is shown in Figure 4.5. The use of a single bolt is lighter than two. The weight saving difference between Concept 1 and 2 is larger than the difference between Concept 4 and 5, due to the shorter length and lighter weight of the bolts used in the latter two concepts.

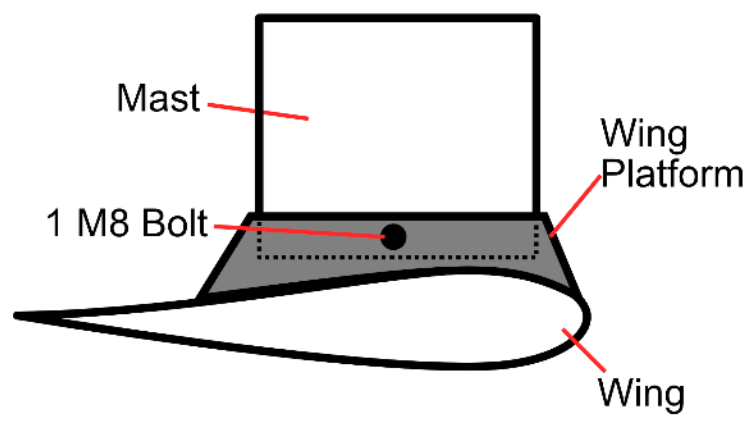

Figure 4.5 - Side Profile Of Design ConCEPt 5 
As seen in Figure 4.6, this concept features a plate bolted onto an extruded mast which features a hook at the rear, and a front mounted bolt. The mast is hooked onto the trailing edge of a matching wing mounted plate, then rotated forward and bolted in place. This allows you to use a single small bolt to hold the mast in place, which saves weight over previous designs. This design can use a cheap extruded mast and thus does not require the expensive CNC masts of Concepts 4 and 5.

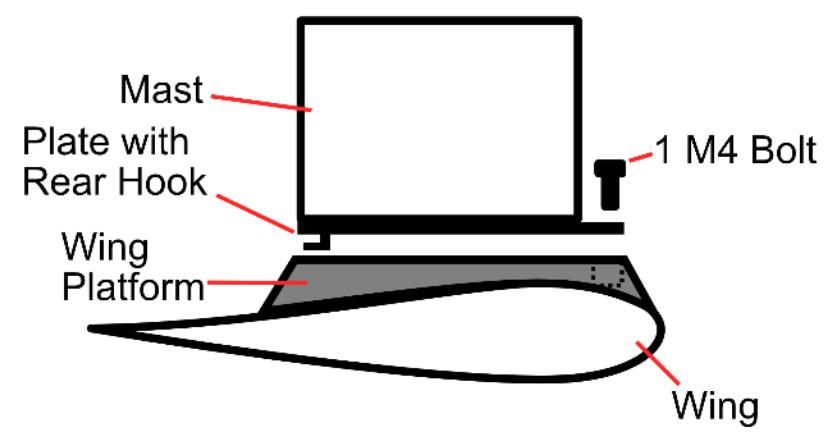

Figure 4.6 - Side Profile Of Design Concept 6

\section{Concept 7-Magazine Inspired Sliding Dovetail}

This concept takes inspiration from rifle magazine attachment mechanisms. This design features an attachment base in the wing, along with a matching receptacle mounted to the mast, as shown in Figure 4.7. The base and receptacle slide into each other, and a spring tensioned pin is used to lock the sliding parts together. This design does add additional weight to the overall structure when compared to all

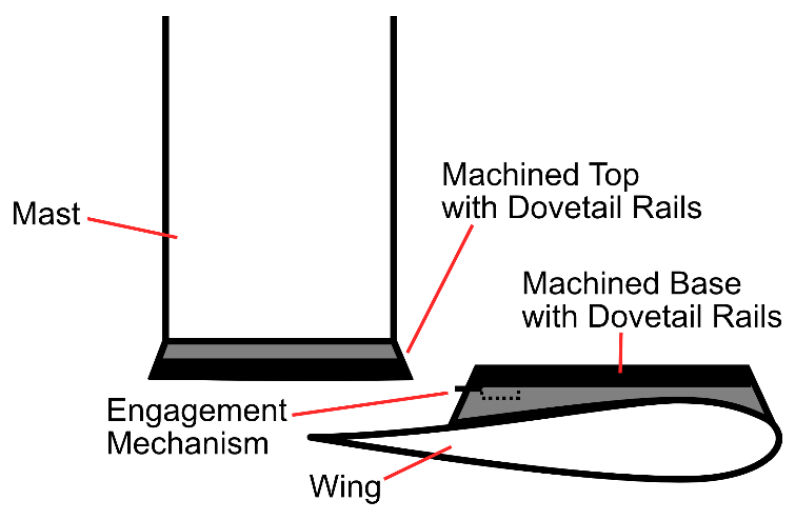

Figure 4.7 - Side Profile of Design Concept 7 
previous concepts listed, but due to its dovetail design, it'd be very strong, yet easy to detach and reattach. One main disadvantage of this design is the additional manufacturing steps required to create the two dovetail interface plates.

\section{Concept 8 - Magazine Inspired Clip}

Like the previous concept, this design is also inspired by rifle magazine attachment mechanisms and features a rear hook with a forward clip, shown in Figure 4.8. The mast is hooked onto the rear of the attachment well and swung forward to click in place. This design is very quick to attach and detach, although similarly to Concept 7 , it does require additional manufacturing steps. A clip mechanism is inherently less robust than the dovetail of Concept 7, however a clip design is easier for a user to align and takes less effort to assemble.

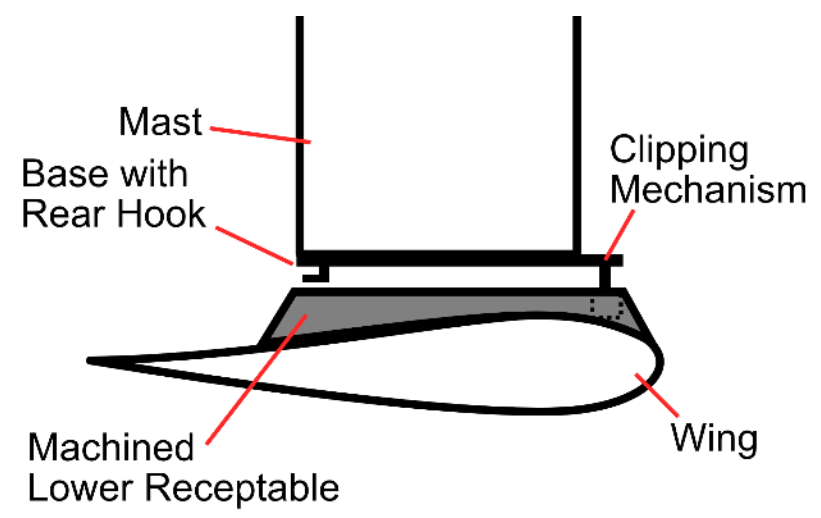

Figure 4.8 - Side Profile of Design ConCePt 8 


\subsection{Concept Selection}

The concepts were rated using the rating system developed in the previous section. Each concept was given a score in each metric, and that score was multiplied by the weight of the respective metric. This process is shown in Tables 4.1 and 4.2.

Table 4.1 - Design Metrics Weighting per Concept

\begin{tabular}{|c|c|c|c|c|c|c|c|c|c|c|c|}
\hline \multirow[t]{2}{*}{ Metrics } & \multirow{2}{*}{$\begin{array}{l}\text { Rel. } \\
\text { Weight }\end{array}$} & \multicolumn{2}{|c|}{ Concept 1} & \multicolumn{2}{|c|}{ Concept 2} & \multicolumn{2}{|c|}{ Concept 3} & \multicolumn{2}{|c|}{ Concept 4} & \multicolumn{2}{|c|}{ Concept 5} \\
\hline & & Score & W.Score & Score & W.Score & Score & W.Score & Score & W.Score & Score & W.Score \\
\hline $\begin{array}{l}\text { Fatigue } \\
\text { Resistance }\end{array}$ & $17 \%$ & 4 & 0.69 & 3 & 0.52 & 4 & 0.69 & 5 & 0.86 & 4 & 0.69 \\
\hline Time to Install & $14 \%$ & 3 & 0.42 & 4 & 0.56 & 4 & 0.56 & 3 & 0.42 & 4 & 0.56 \\
\hline $\begin{array}{l}\text { Manufacturing } \\
\text { Cost }\end{array}$ & $8 \%$ & 5 & 0.39 & 5 & 0.39 & 4 & 0.31 & 1 & 0.08 & 2 & 0.16 \\
\hline Weight & $20 \%$ & 3 & 0.61 & 4 & 0.81 & 4 & 0.81 & 4 & 0.81 & 4 & 0.81 \\
\hline $\begin{array}{l}\text { Manufacturing } \\
\text { Time }\end{array}$ & $8 \%$ & 4 & 0.31 & 5 & 0.39 & 3 & 0.23 & 2 & 0.16 & 3 & 0.23 \\
\hline Strength & $23 \%$ & 5 & 1.17 & 3 & 0.70 & 4 & 0.94 & 5 & 1.17 & 4 & 0.94 \\
\hline Looks/Elegance & $2 \%$ & 3 & 0.05 & 5 & 0.08 & 5 & 0.078 & 3 & 0.05 & 3 & 0.05 \\
\hline Hydrodynamics & $11 \%$ & 4 & 0.44 & 4 & 0.44 & 4 & 0.44 & 3 & 0.33 & 4 & 0.44 \\
\hline Total & & 31 & 4.08 & 33 & 3.89 & 32 & 4.06 & 26 & 3.88 & 28 & 3.88 \\
\hline
\end{tabular}


Table 4.2 - Design Metrics Weighting Per Concept (Cont'D)

\begin{tabular}{|c|c|c|c|c|c|c|c|}
\hline \multirow[t]{2}{*}{ Metrics } & \multirow{2}{*}{$\begin{array}{l}\text { Rel. } \\
\text { Weight }\end{array}$} & \multicolumn{2}{|c|}{ Concept 6} & \multicolumn{2}{|c|}{ Concept 7} & \multicolumn{2}{|c|}{ Concept 8} \\
\hline & & Score & W.Score & Score & W.Score & Score & W.Score \\
\hline $\begin{array}{l}\text { Fatigue } \\
\text { Resistance }\end{array}$ & $18 \%$ & 5 & 0.86 & 4 & 0.69 & 4 & 0.69 \\
\hline Time to Install & $14 \%$ & 4 & 0.56 & 5 & 0.70 & 5 & 0.70 \\
\hline $\begin{array}{l}\text { Manufacturing } \\
\text { Cost }\end{array}$ & $8 \%$ & 1 & 0.08 & 3 & 0.23 & 3 & 0.23 \\
\hline Weight & $20 \%$ & 3 & 0.61 & 4 & 0.81 & 4 & 0.81 \\
\hline $\begin{array}{l}\text { Manufacturing } \\
\text { Time }\end{array}$ & $8 \%$ & 2 & 0.16 & 3 & 0.23 & 4 & 0.31 \\
\hline Strength & $23 \%$ & 4 & 0.94 & 5 & 1.17 & 4 & 0.94 \\
\hline Looks/Elegance & $2 \%$ & 4 & 0.06 & 5 & 0.08 & 5 & 0.08 \\
\hline Hydrodynamics & $11 \%$ & 5 & 0.55 & 5 & 0.55 & 5 & 0.55 \\
\hline Total & & 28 & 3.81 & 34 & 4.47 & 34 & 4.31 \\
\hline
\end{tabular}

The concept with the highest score was Concept 7, the magazine inspired sliding dovetail. The reasoning behind the scoring for this concept is as follows:

- Fatigue resistance: A score of 4 is given as there are large surfaces areas in contact, secured using a captive clip, with the dovetail joint is loaded under tension.

- Time to install: A score of 5 is given as the two parts are simply slid together and click into place, which takes less than one second.

- Manufacturing cost: A score of 3 is given as the design can use the cheap to produce extruded mast but requires CNC machining for both the upper and lower attachments of the design.

- Weight: A score of 4 is given. The design requires CNC machined adapters to be permanently attached to the wing to attach the machined base. 
- Manufacturing time: Score of 3 as CNC machining operations are used, however there are few tool changes. A dovetail can be milled using a single angled dovetail cutter, and the remaining curvature can be milled using one tool.

- Strength: Score of 5, as both parts have a large surface area of friction with a strong captive clip preventing movement on a non major loading axis.

- Looks/Elegance: Score of 5 as the design is simple and features a hidden clip mechanism. There are no visual disturbances from bolts or fasteners.

- Hydrodynamics: Score of 5, as the design has smooth curves with no bored holes or protrusion in fluid flow. 


\section{Preliminary Design and Refinement}

\subsection{Loading Cases}

In order to quantify the feasibility of the chosen concept design, it will be subjected to a series of load analyses. These analyses are geared to represent the most extreme loads the mechanism will experience throughout its use, and are divided into tensile, compressive, lateral bending, and longitudinal bending loads. The max allowable loads of the critical cases are summarised in Table 5.1.

\section{Vertical Loading Case}

In this case, loads are applied along the vertical axis of the design to determine its susceptibility to both compressive and tensile loads. The compressive loading parameters are $F_{\text {vertical }}=g\left(1.3 m_{\text {rider }}+\right.$ $\left.m_{\text {mast }}+m_{\text {board }}\right)$. The configuration for this loading analysis is shown in Figure 5.1 overleaf.

Using the data outlined in the Literature Review section, the maximum total load is $F_{\text {vertical }}=1,025 \mathrm{~N}$. Adding a factor of safety of $30 \%$ gives us $F_{\text {ult.vertical }}=1,333 \mathrm{~N}$. However, on top of this worst-case scenario, the apparatus can still experience additional tensile loads imparted by the lifting forces of the wing under the water, due to things such as changes in angle of attack, or turbulence. Thus, an additional safety factor of $30 \%$ is added, bringing the analysised load to $1,733 \mathrm{~N}$. The factor of safety used during analysising is 1.3, as the Al-6061-T6 alloy used is a highly reliable material, where loading conditions are not severe, and weight is an important consideration [8]

Regarding tensile loads, it is not currently possible to calculate an estimate for the tensile load the attachment will experience. Thus, the same $1,733 \mathrm{~N}$ load will be applied in tension. 


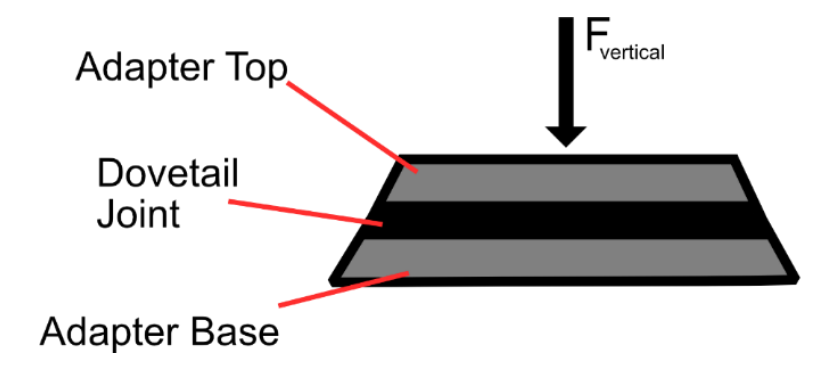

Figure 5.1 - SCHEMATIC OF VeRTICALly LOADEd ANALysis

\section{Lateral Loading Case}

There are two possible worse case scenarios for a lateral loading case. First is the entire weight of a $76.66 \mathrm{~kg}$ rider being applied to the outer edge of the board. This situation is well outside the bounds of normal, but it is certainly not impossible, and is shown in Figure 5.1 overleaf. Considering a 30\% factor of safety, the torque generated in this condition is: $T_{\text {ult.lateral }}=1.3\left(\operatorname{gm}_{\text {rider }} \frac{1}{2} L_{\text {board width }}\right)$.

The second worse case scenario that of a rider stepping on the centre of the mast while the board is laying on its side, seen in Figure 5.2 overleaf. The torque generated in this situation including a $30 \%$ factor of safety is: $T_{\text {ult.lateral }}=1.3\left(g m_{\text {rider }} \frac{1}{2} L_{\text {mast }}\right)$.

Substituting into the equations for both scenarios, we obtain torque values of $241 \mathrm{Nm}$ and $250 \mathrm{Nm}$. The larger torque load of the second case will be used as the analysising torque. 


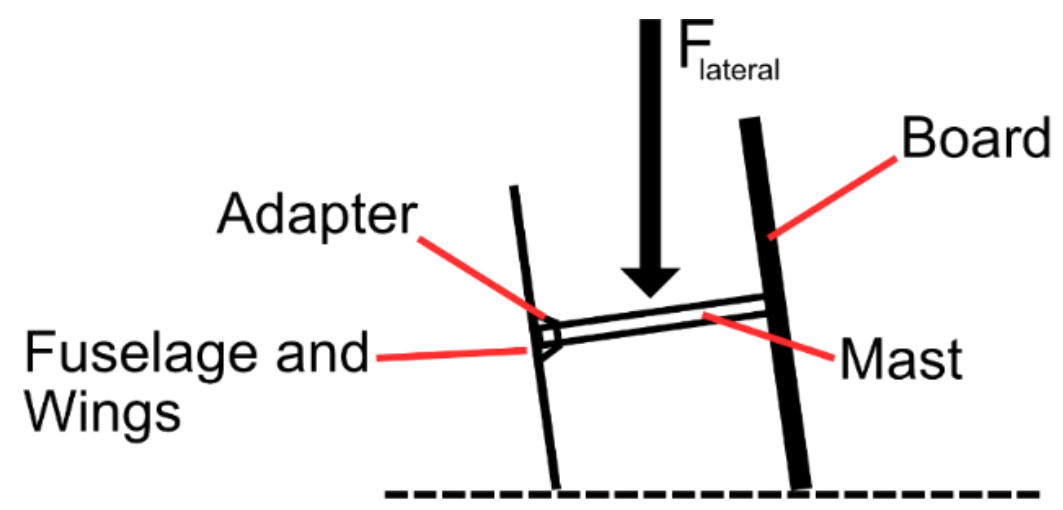

Figure 5.2 - Schematic of LAterally LoAded AnAlysis (1)

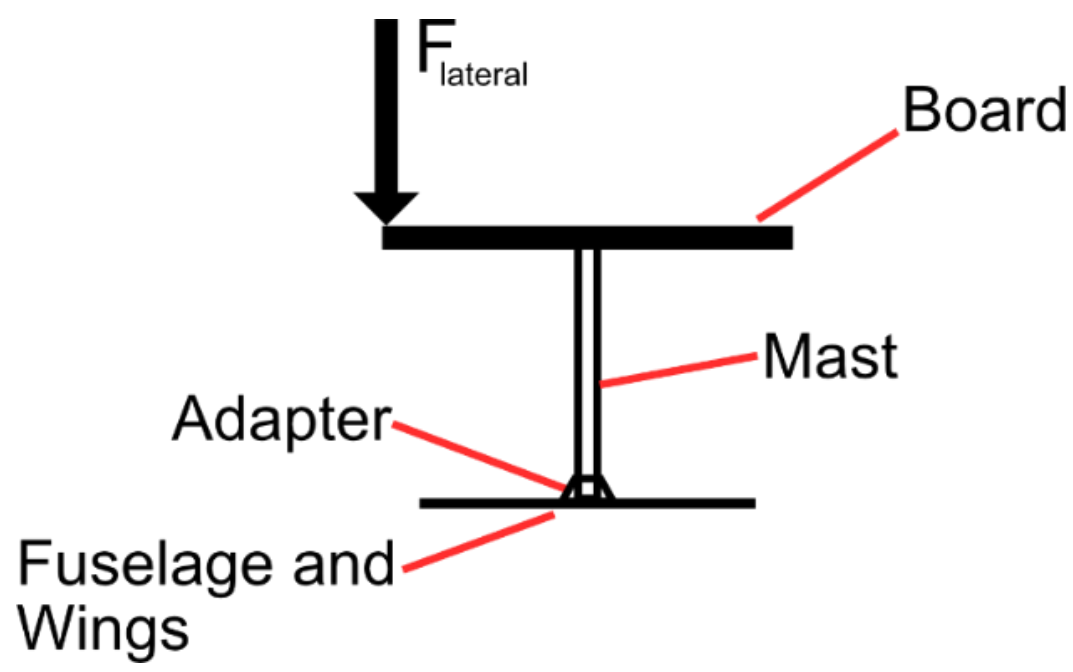

FiguRe 5.3 - SChEMAtic OF LATERAlLy LoAded ANAlysis (2)

TABle 5.1 - MaX Allowable Loads of Critical CaSes

\begin{tabular}{|l|l|}
\hline Vertical Forces & Lateral Torque \\
\hline $1733 N$ & $250 \mathrm{Nm}$
\end{tabular}




\subsection{Detailed Design}

Given the concept parameters, a series of designs were drafted up in Solidworks. In order to meet weight targets, the design went through a series of revision steps to shave off material while maintaining enough strength to satisfy the load bearing parameters. Material was shaved off by alternating between manual adjustment of the part parameters and simulation analysis. First, a baseline shape was constructed, and the load cases mentioned previously were analysised using the Solidworks Simulation package. The results were observed, and additional material or modifications were made to the design to reduce weight and/or optimise shape until the design could not be feasibly improved any further. As the factor of safety being used is 1.3, and that the yield strength of Al-6061-T6 is 275MPa, 211.5MPa will be considered the maximum allowable stress during analysis.

The design went through four iterations, the fourth, shown in Figure 5.4, was the final design iteration reached. It was determined to be infeasible to shave more weight off this design without compromising either strength or features. Other design iterations are shown in the appendix. The final changes in this iteration include:

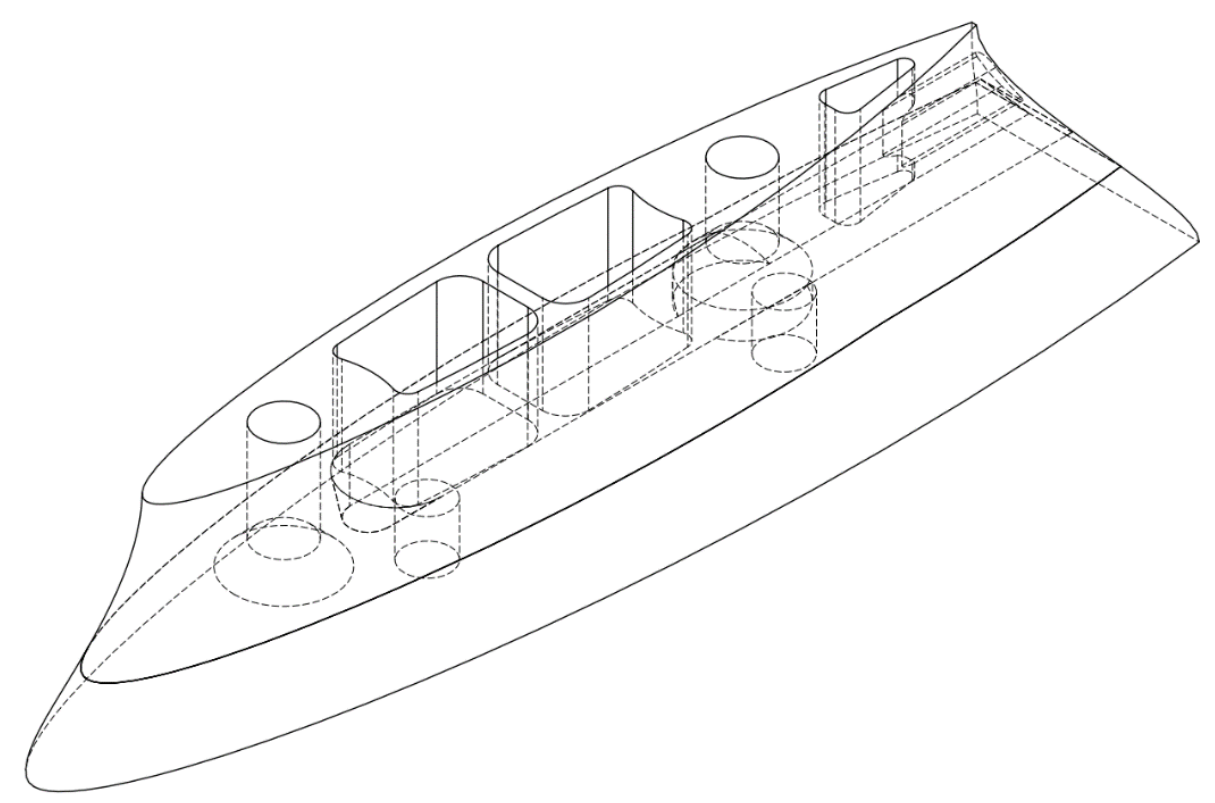

Figure 5.4 - Iteration 4 And Final Design Concept 
- A redesigned base section to reduce both mass and the side of the matching socket that must be sculpted into the wing surface

- The upper surface has been redesigned to use countersunk M6 bolts

- The dovetail has been narrowed and shortened

The final mass of this design is $104 \mathrm{~g}$. This is a miniscule $35 \%$ of the original weight target of $300 \mathrm{~g}$. A full overview of this design is shown in Figures 5.7 and 5.8. The performance of this extremely lightweight design will be explored in the next section.

As mentioned, the design cannot be shaved down any more for both physical strength reasons, but also feature compatibility reasons. As shown in Figure 5.5, the rear slot through with the thumb switch is connected to the internal spring mechanism, shown in Figure 5.6, is very close to the edges of the trailing edge of the upper adapter. The slot cannot be narrowed further without compromising the diameter of the lever component, and it cannot be shrunk vertically without further reducing the leverage the user will have to operate the spring. Thus, the trailing edge reason cannot be shrunk any further without compromising these features.

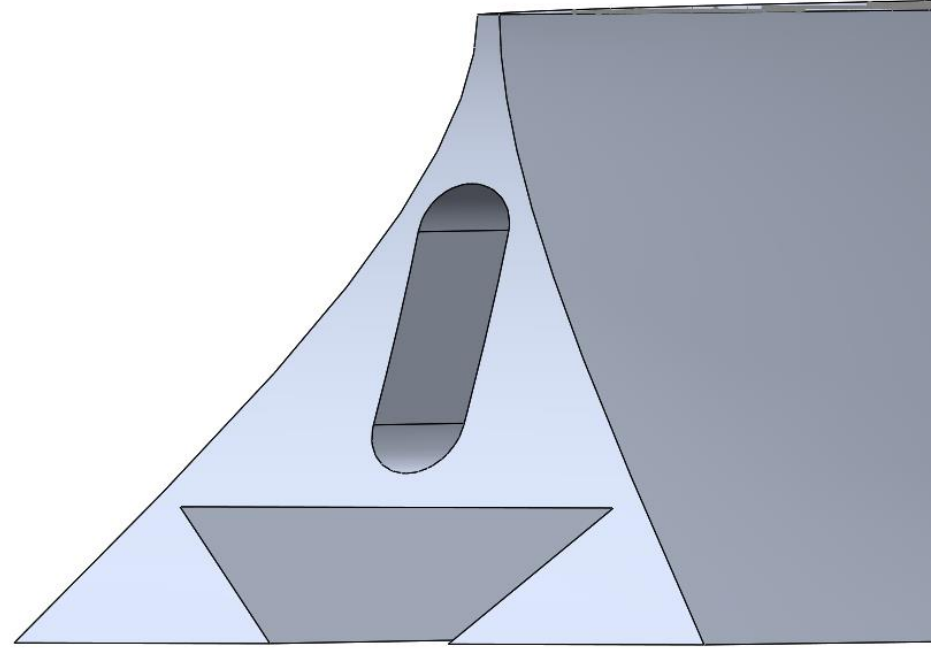

Figure 5.5 - Diagram of TAIL END of Final Design 


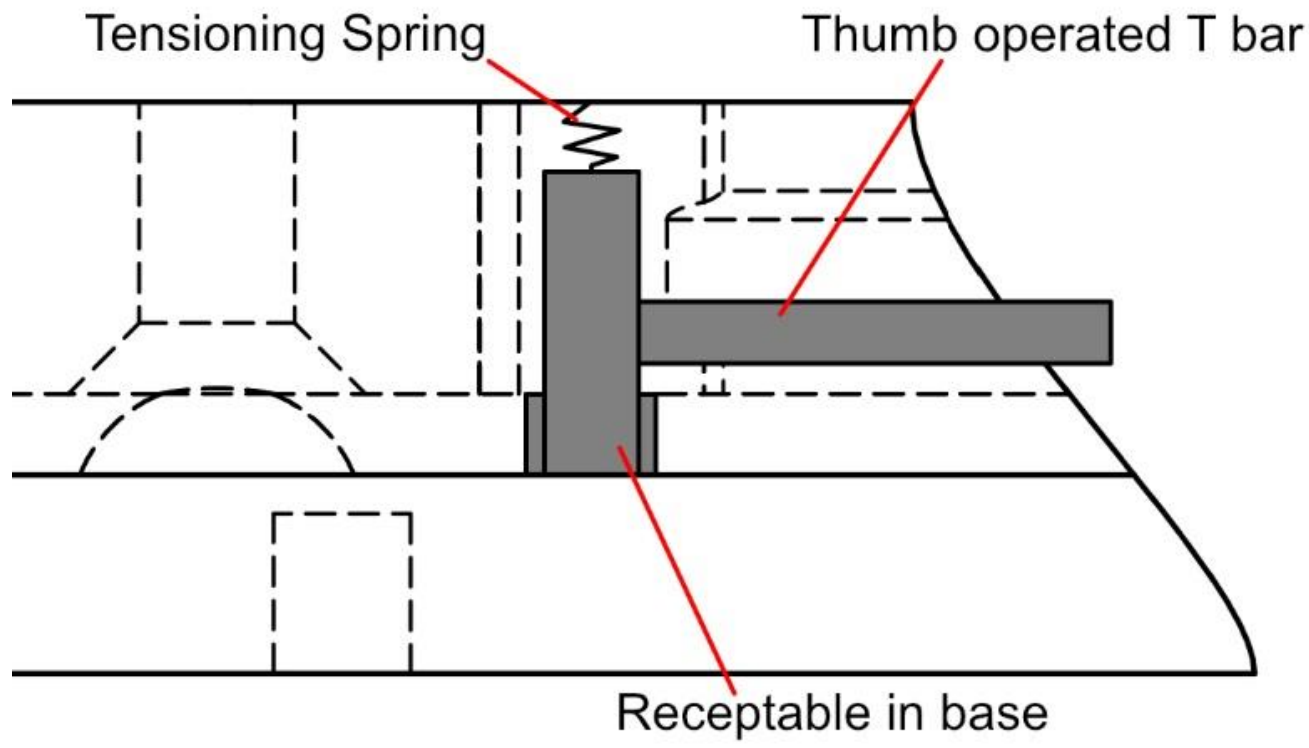

Figure 5.6 - Diagram Showing SeCURing Mechanism 

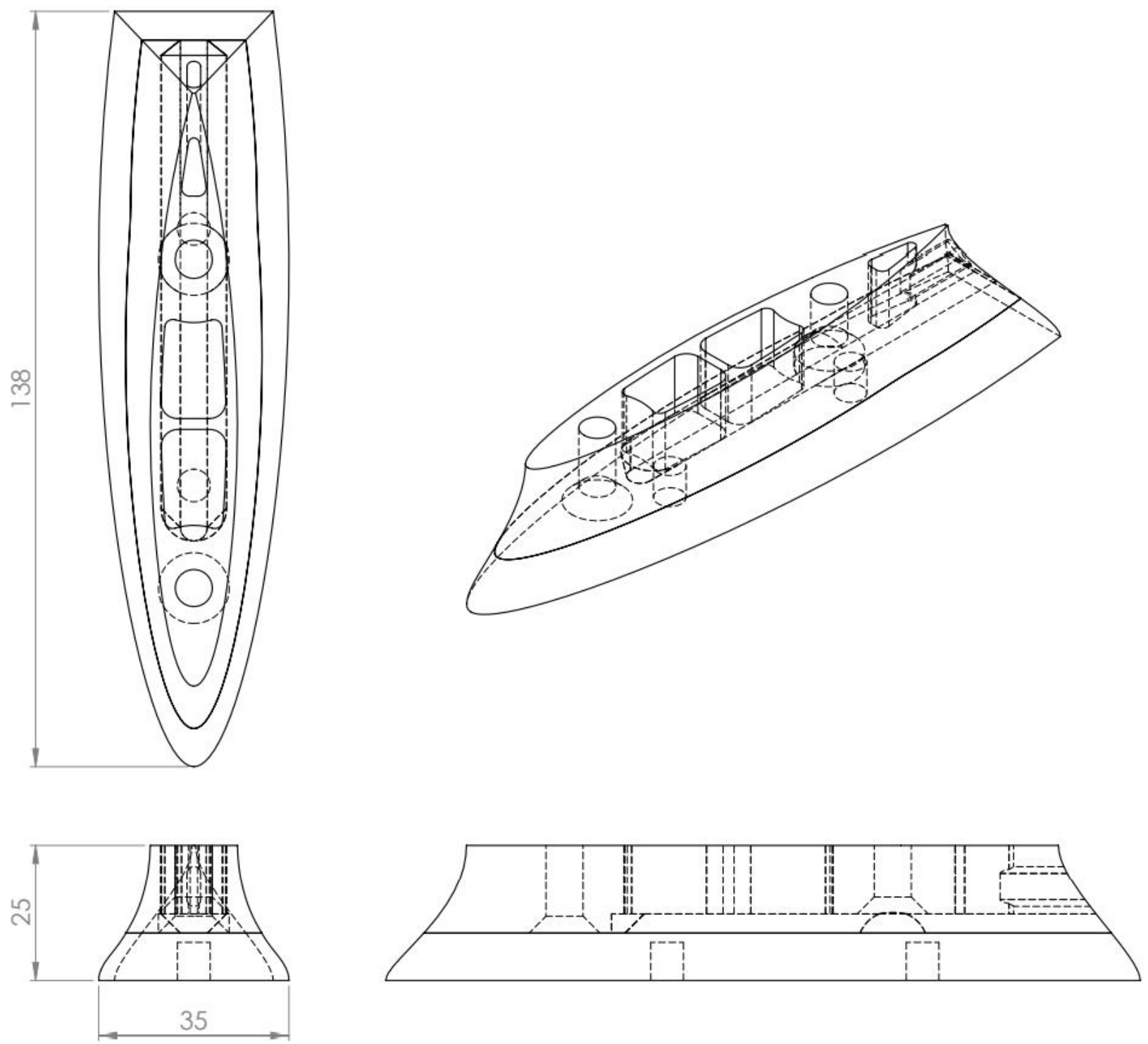

Figure 5.7 - Overview of Final Attachment Mechanism Design 

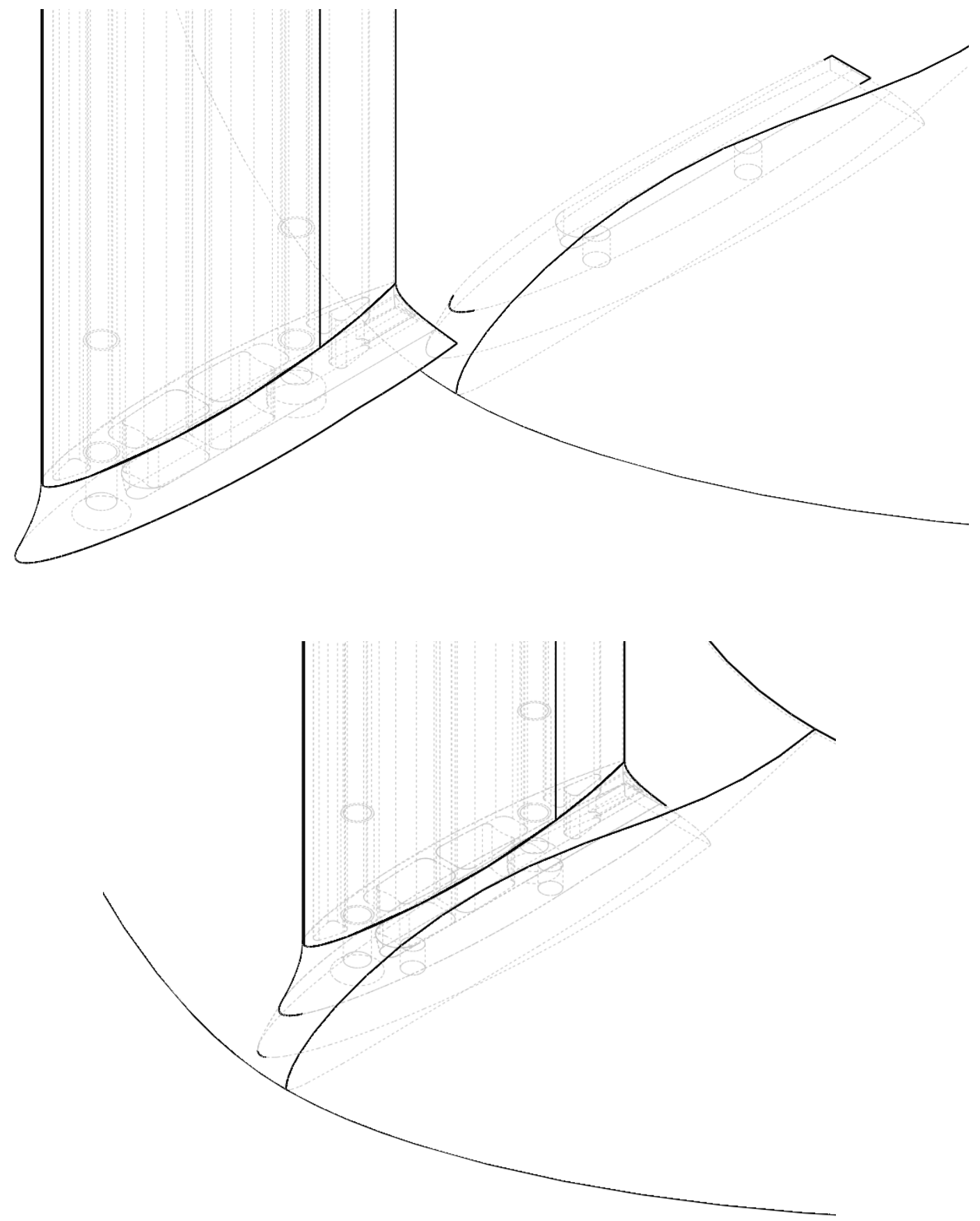

Figure 5.8 - Diagram Showing Mechanism In Both Detached and Attached Positions 


\section{Presentation, Analysis and Discussion of Analytical Data}

Both preliminary and more detailed analysis results will now be discussed. Both Solidworks and ANSYS have been used to analyse the final design. The reasoning behind this is multi faceted, regarding Solidworks simulation:

- Solidwork's simulations are built in, and quick to configure.

- Simulating in Solidworks greatly speeds up the design iteration process, as no exporting and importing of CAD files is needed.

The hitch with relying on Solidworks is that it is an overall less robust simulation package than ANSYS. Solidworks is used for the initial design work, and once the conceptualised design is relatively robust, it is then exported over to ANSYS for more detailed simulation work.

\subsection{Solidworks Analysis Results}

The preliminary Solidworks analyses comprised of compressive, tensile, and lateral analyses as mentioned. Simulations were conducted using Aluminium 6061-T6 with an allowed yield strength of 211.5MPa, the material of choice for manufacturing.

\section{Analysis Configuration}

The adapter was fixed uniformly on its lower surface to simulate being mated to the upper surface of a wing. Both translation and rotation were set to zero. Forces were applied to the upper surface and bolt holes vertically for compressive analysis. Torque for lateral analysis was also applied to the same surfaces, along a logitudinal axis drawn along the top face. Forces were applied vertically to only the bolt hole surfaces for the tensile analysis. These parameters are visualised in Figures 6.1 and 6.2 


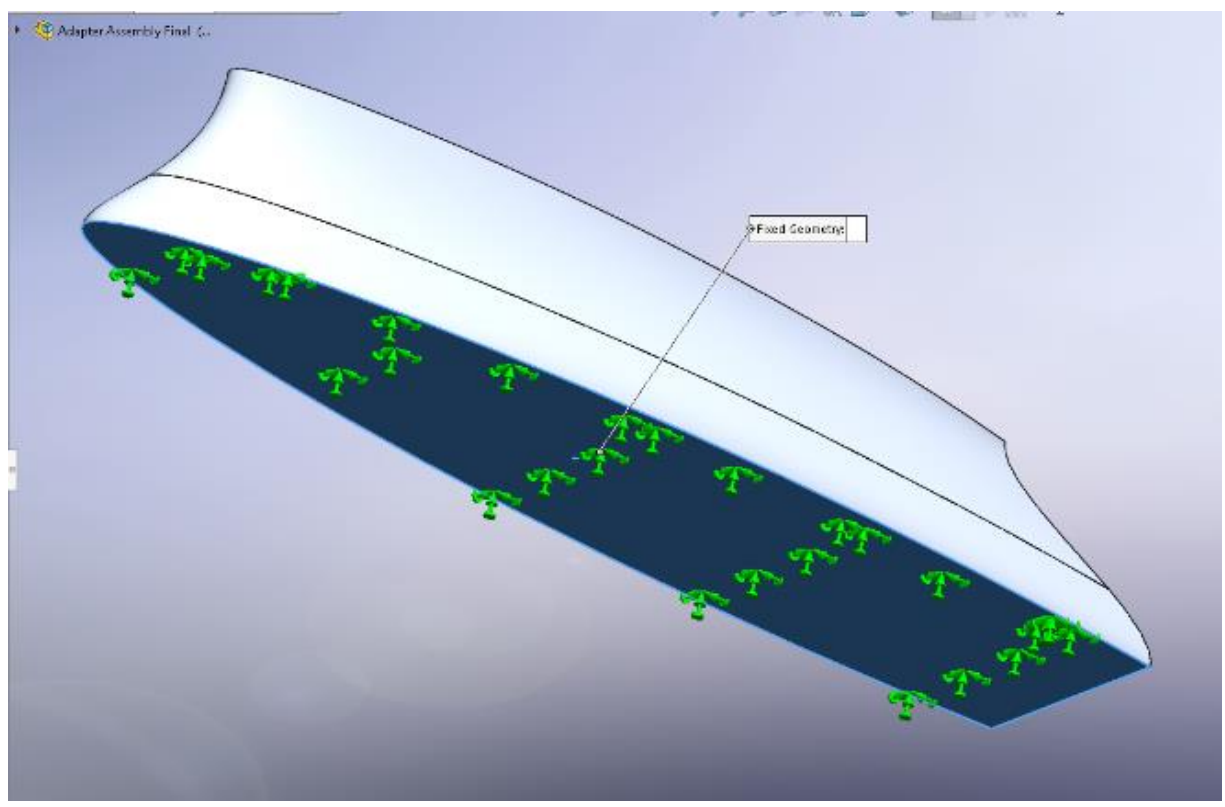

Figure 6.1 - Visualisation OF FiXed LOWER SURfaCe

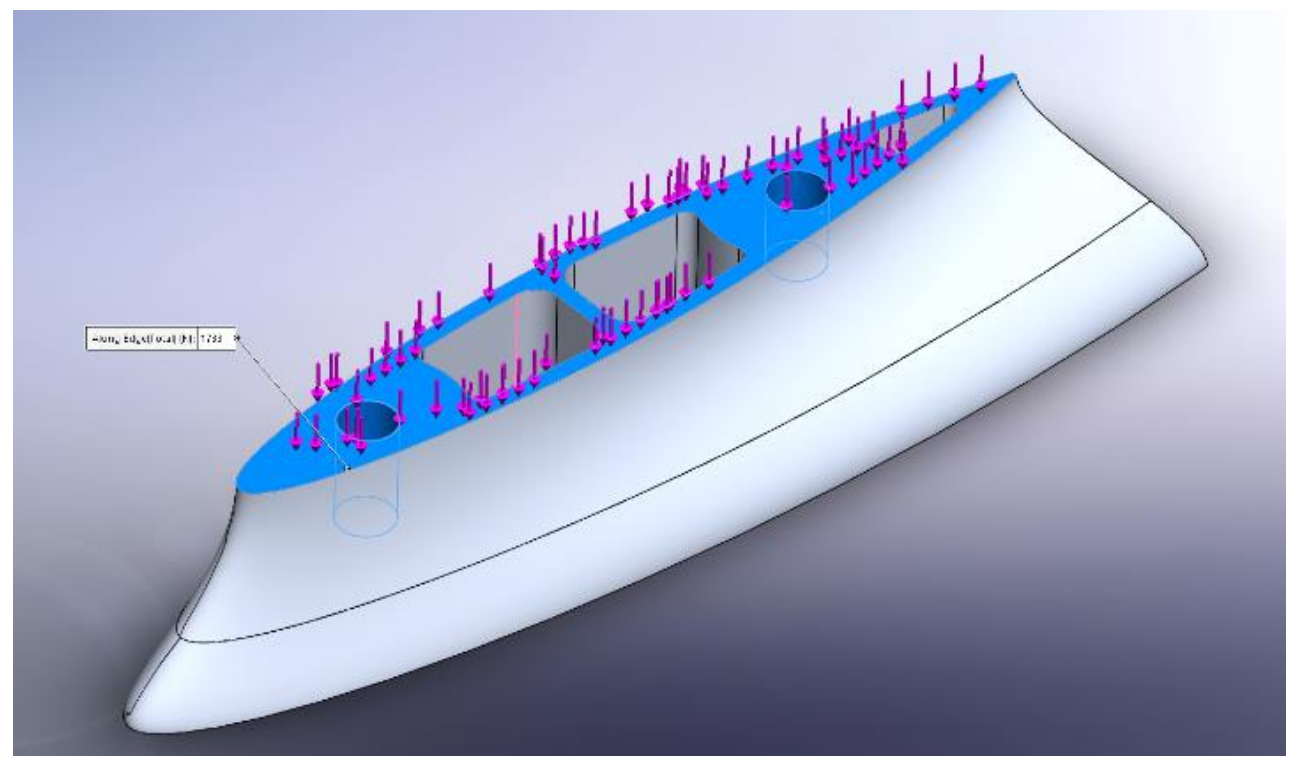

Figure 6.2 - Visualisation Of LOAd ApPLICATION 


\section{Meshing}

Solidworks provides standard presets for meshing. The curvature-based mesh preset was chosen, and modified with the parameters shown in Table 6.1 below.

TABLE 6.1 - SOLIDWORKS MeSh DATA

\begin{tabular}{|c|c|c|}
\hline Option/Setting & Default Preset & Modified Preset \\
\hline Max Element Size & $7.522 \mathrm{~mm}$ & $5.233 \mathrm{~mm}$ \\
\hline Min Element Size & $1.505 \mathrm{~mm}$ & $1.047 \mathrm{~mm}$ \\
\hline Min \# of elements in a circle & 8 & 8 \\
\hline Element size growth ratio & 1.6 & 1.6 \\
\hline \# of Jacobian points & 4 & 4 \\
\hline
\end{tabular}

The preset was modified after a brief convergence study was conducted. The defaults failed to converge, and the modified preset shown was the largest element size which guaranteed convergece along with less than $5 \%$ delta in analysis result output. In addition to the above, Jacobian sizes of 4,16 , and 29 were tested, and results also were within $5 \%$ tolerance, thus 4 points were used.

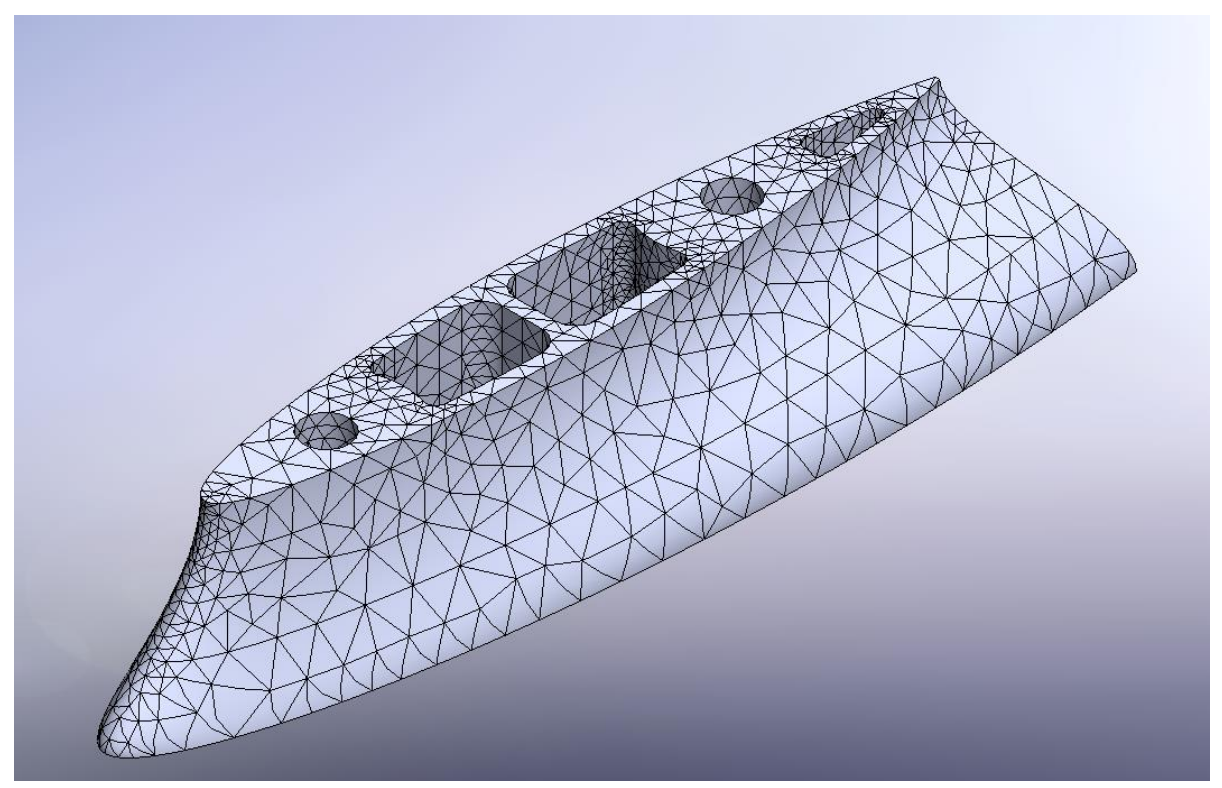

FigURE 6.3 - SOLIDWORKS MESHING ResULt 


\section{Compressive Loading}

Under compressive loading, the design experienced a maximum stress of 5.584MPa, well under the 211.5MPa limit. This may be considered an excessive margin, however, the adapter, due to its elongated and narrow nature, is stronger in the vertical axis and weaker in both lateral and longitudinal axes due to increased material in these respective axes. Optimising for load in one axis affects the results of loading in the other axes, thus more material cannot be shaved off to reduce the longitudinal or vertical strength without sacrificing lateral strength.

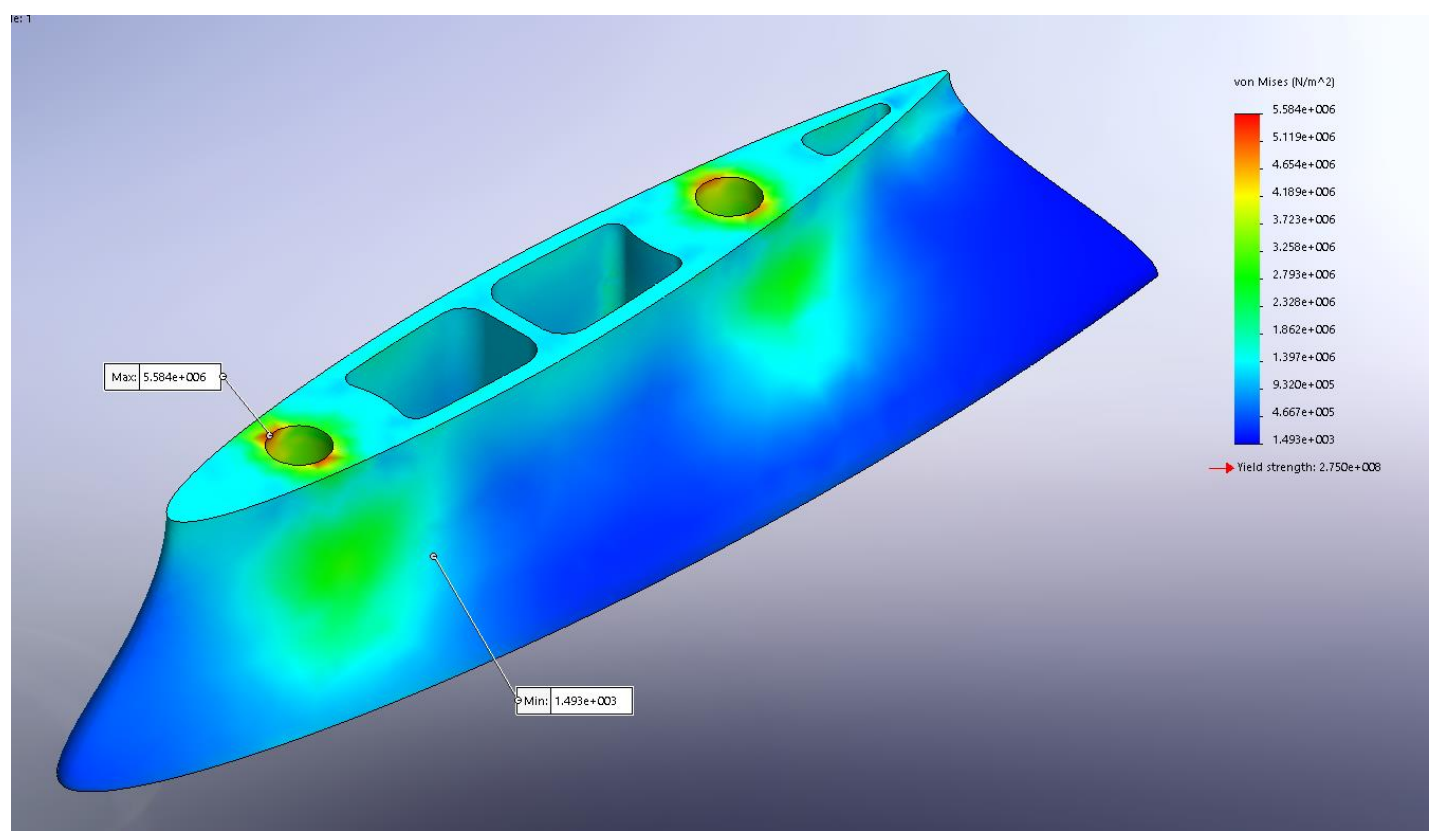

FigURE 6.4 - SOLIDWORKS StRESS DiSTRIBUTION OF COMPRESSIVE LOADING

\section{Tensile Loading}

The tensile loading analysis produced a maximum stress of 1.291MPa, the stress distribution of which is shown overleaf in Figure 6.5. This analysis was completed similarly to the compressive loading analysis, the difference being the upward load was added only to the bolt threads. Thus, it is possible to use smaller bolts to reduce weight, however this would remove compatibility with the existing Triton mast. 


\section{Lateral Loading}

The lateral analysis resulted in a peak stress of $159.6 \mathrm{MPa}$. This is $75 \%$ of the allowable yield strength of 211.5MPa, as such the current design iteration is approaching its maximum limits. The stress distribution of this analysis is shown in Figure 6.6 overleaf. The highest point of stress occurs within the threads of the bolt holes, shown in Figure 6.7, also overleaf.

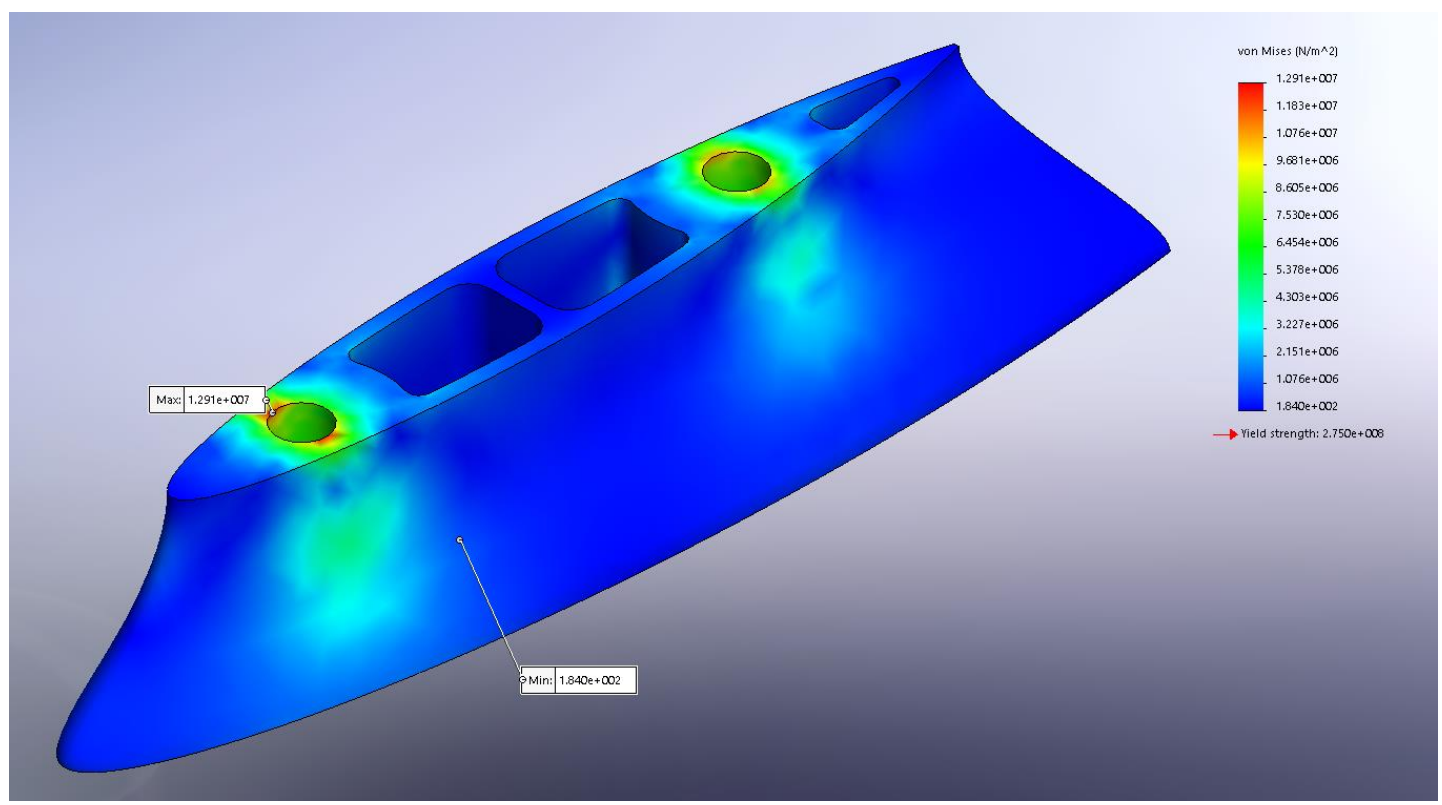

Figure 6.5 - SOlidWORKS StRESS Distribution OF TENSILE LOADING 


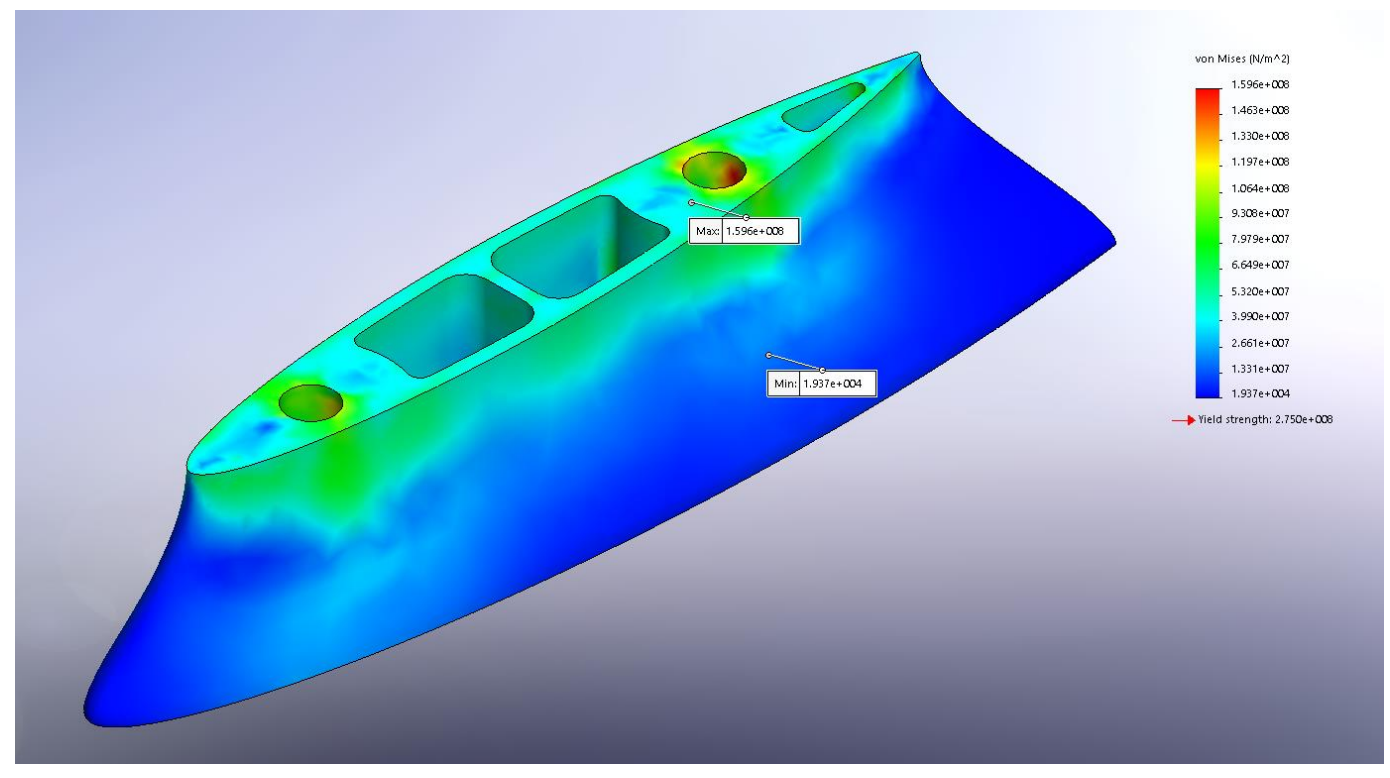

FigURE 6.6 - SOLIDWORKS STRESS DistRIBUTION OF LATERAL LOADING

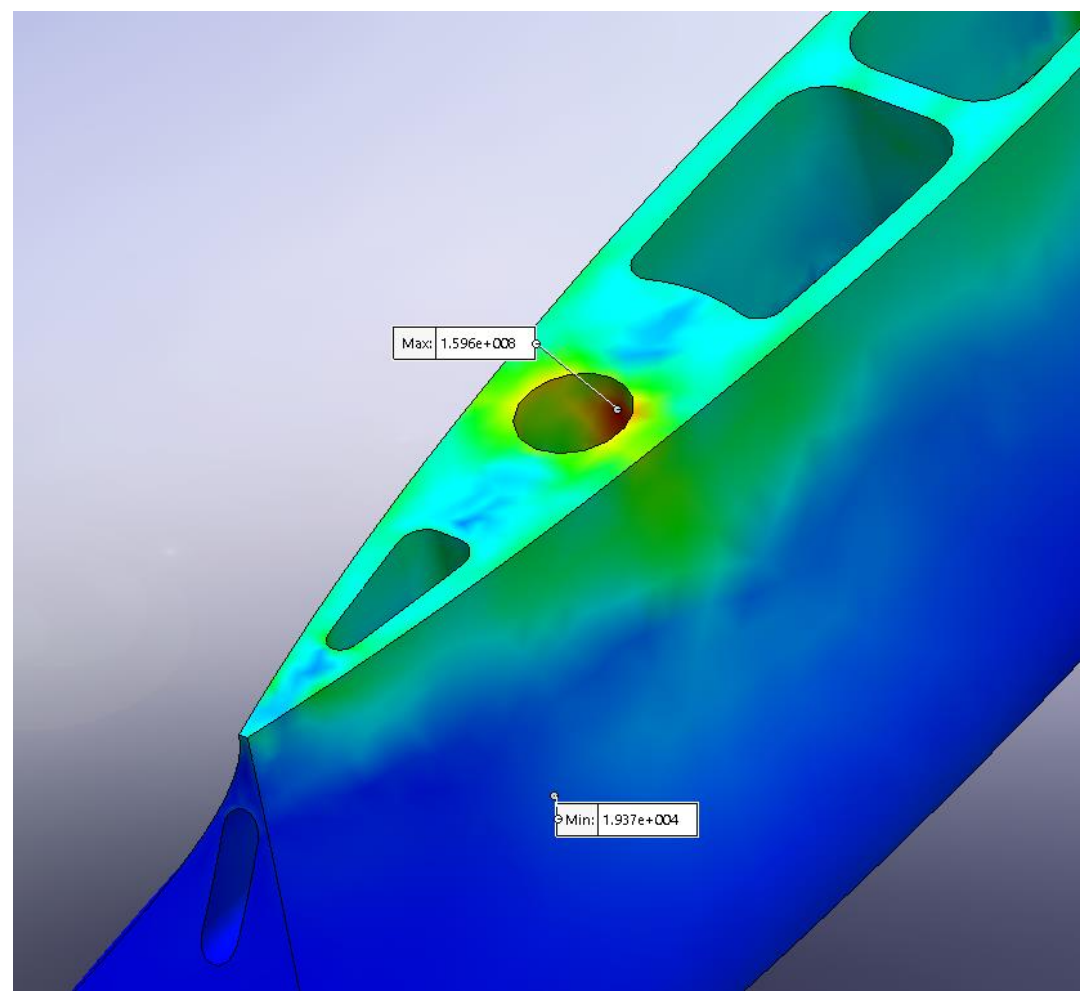

Figure 6.7 - Alternate Angle of Figure 6.6 Showing Rear Bolt Hole 


\subsection{ANSYS Load Analysis}

\section{Mesh Configuration}

Before analysing can begin, the mesh type and density must first be determined. Due to limitations in the student version of ANSYS Workbench, the maximum number of simulation nodes is limited to 32,000 . Some creativity had to be used to overcome this bottleneck. Various mesh configurations were analysised to ensure accurate simulation while staying under the $32 \mathrm{~K}$ node limit, and the two setups shown in Table 6.2 below were decided upon.

\section{TABLE 6.2 - ANSYS MESH DATA}

$\begin{array}{lll}\text { Option/Setting } & \text { Mesh Configuration A } & \text { Mesh Configuration B } \\ \text { Mesh Compression } & \text { Yes } & \text { Yes } \\ \text { Resolution } & \text { Fast } & \text { Slow } \\ \text { Transition } & \text { Fine } & \text { Fine } \\ \text { Span Angle Center } & \text { Yes } & \text { Yes } \\ \text { Use Adaptive Sizing } & 21,548 & 24,863\end{array}$

Mesh Configuration A and Mesh Configuration B will henceforth be referred to as the "Fast" and "Slow" meshes respectively. These two mesh configurations are pictured overleaf in both Figure 6.8 and 6.9. The Slow mesh results in greater node density around the sharply curved areas of the model, such as the bolt holes, while the Fast mesh provides a more gradual density across the entire model. Both mesh models are used for all analysis steps. As the results from the two mesh configurations are visually very similar, only the Fast mesh screenshots will be displayed in this section. 


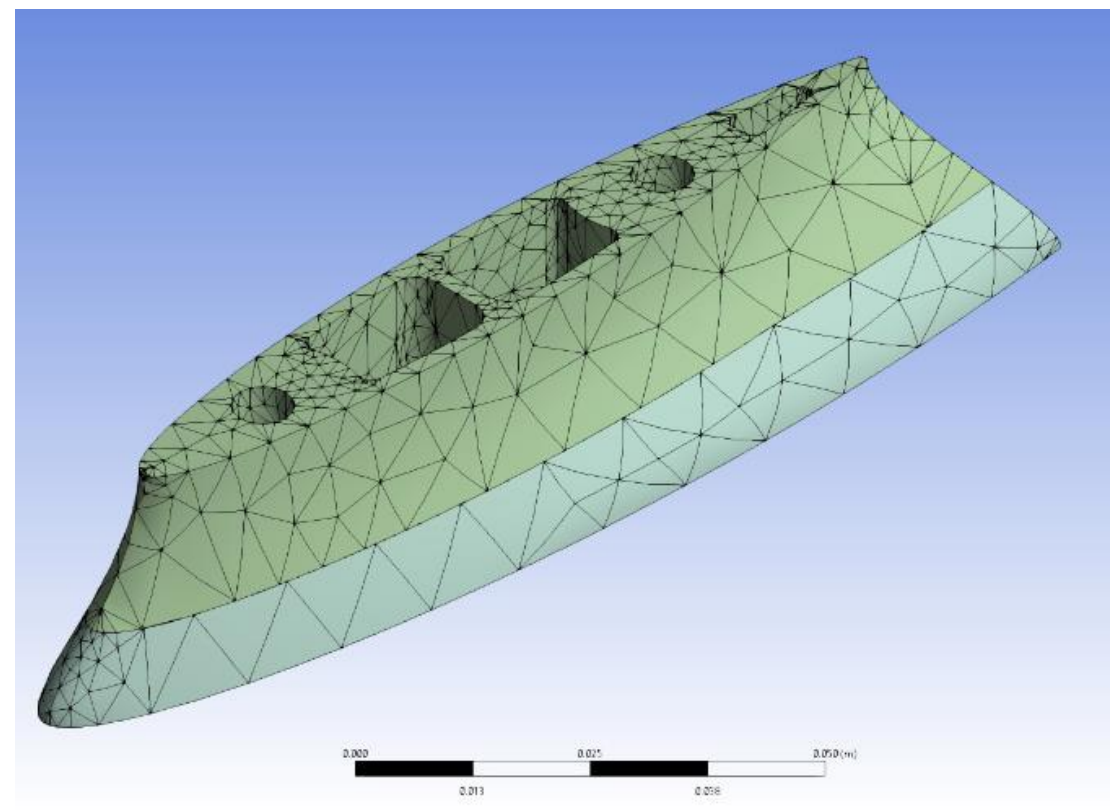

Figure 6.8 - 'Slow' ANSYS MeSh Configuration

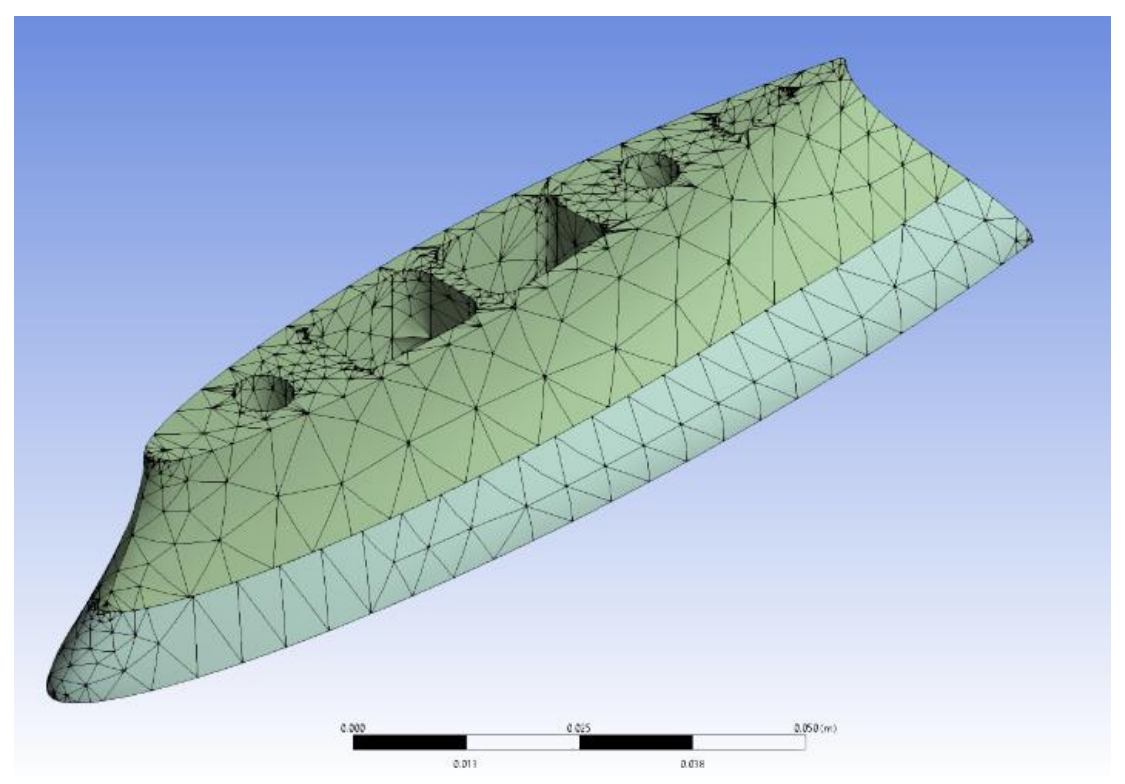

Figure 6.9 - 'FAST’ ANSYS MESH CONFIGURATION 


\section{Compressive Loading}

Boundary conditions used in ANSYS analysis are the same as those used in Solidworks. In compressive analysis, the apparatus is loaded with the full analysising load of $1,368 \mathrm{~N}$. Fixtures are placed on the lower surface of the adapter as well as the underside bolt holes. The compressive load is added across the upper bolt holes as well as the interface surface between the mast and adapter. The figures shown in this section use $0.5 x$ of ANSYS's auto generated deformation scale, which serves as a useful visualisation as to the stress distribution across the mechanism.

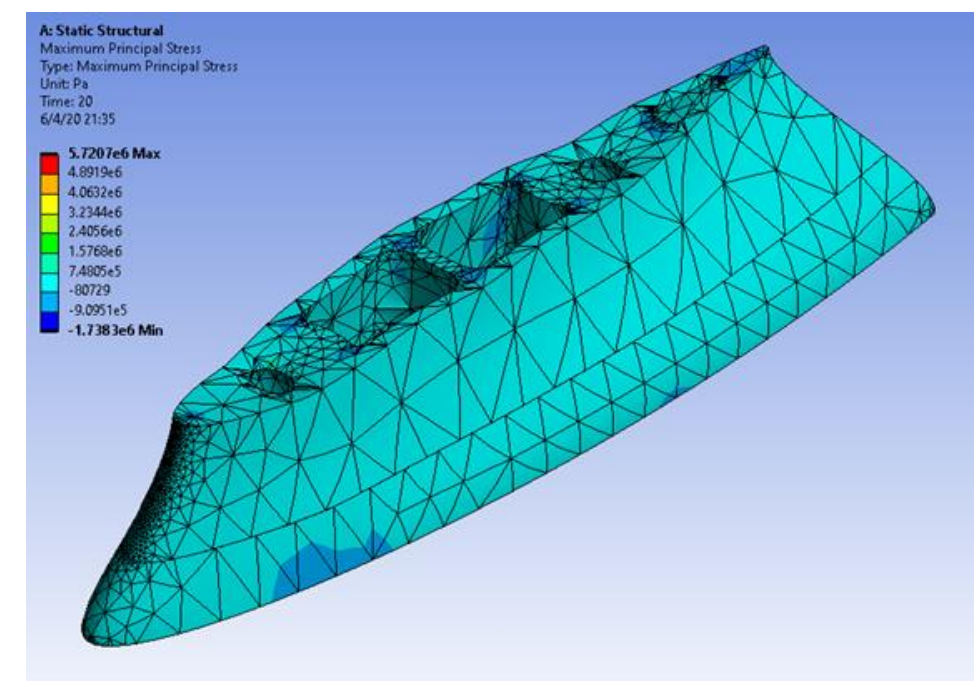

FIGURE 6.10 - ANSYS STRESS DistRIBUTION OF COMPRESSIVE LOADING

The peak stress experienced during this analysis is $4.367 \mathrm{MPa}$ when averaged across both the Slow and Fast mesh settings. The analysising results are tabulated in Table 6.3 overleaf. As seen in Figure 6.10, the highest stress concentration zones occur in the upper portion of the adapter. The design is thus strong enough to endure this load. Maximum deformation occurs around the bolt holes, seen in Figure 6.11 overleaf.

As seen in Table 6.3, there is a trend throughout all analysis that the Fast mesh results in both slightly lower compressive and shear stresses, and lower maximum deformations. The difference is general extremely small with the compressive stress values. 


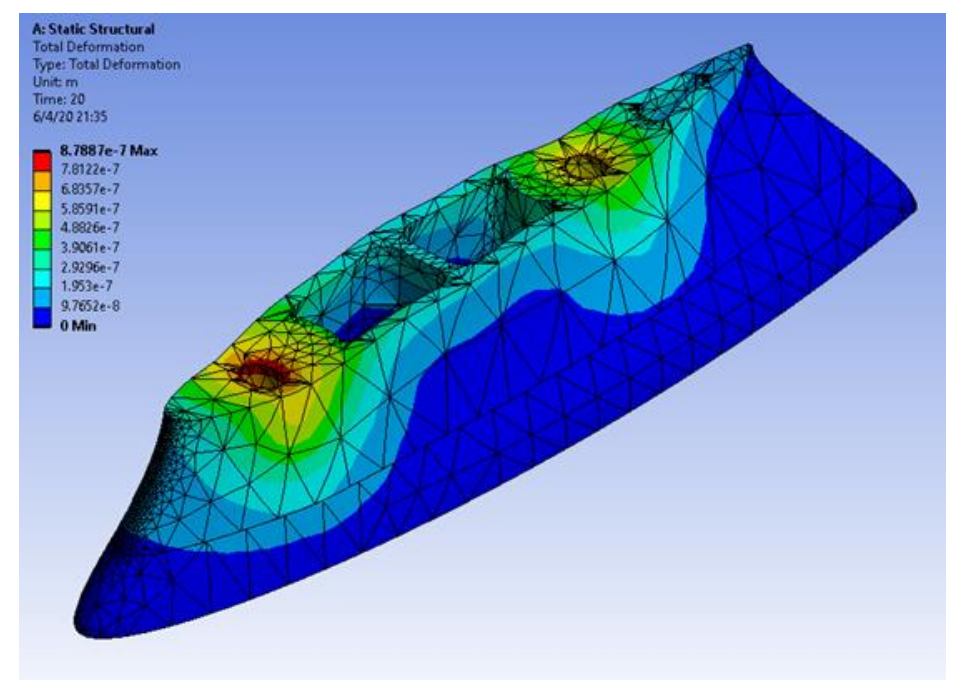

FigURE 6.11 - Deformation OF FAST MESH

TABLE 6.3 - COMPRESSIVE LoAdING SUMmARY

\begin{tabular}{|l|l|l|l|l|l|} 
& Fast & Slow & \multicolumn{1}{l}{ Avg } & \multicolumn{1}{l}{ \% Diff } & \multicolumn{2}{l}{ \% of yield } \\
\hline Max Stress (MPa) & 5.57 & 6.00 & 5.79 & -7.8 & 2.74 \\
\hline Avg Stress (KPa) & 8.95 & 14.75 & 11.86 & -64.7 & 0.01 \\
\hline Avg Shear (KPa) & -0.51 & 11.82 & 5.65 & $2,430.0$ & - \\
\hline Max Def $(\mathrm{mm})$ & 0.00088 & 0.00087 & 0.00088 & 0.7 & - \\
\hline
\end{tabular}

\section{Tensile Loading}

The tensile results are quite different to the compressive results. With the $1,368 \mathrm{~N}$ load applied to only the bolt holes, the adapter experiences a max stress of $11.44 \mathrm{MPa}$ when averaged across the Slow and Fast Analysis. This result is shown in Table 6.4. This peak average value is higher than the compressive results, as the same load is applied to a smaller area in tension as opposed to compression. The lower portion of the adapter is experiencing higher localised forces than previously, where the stress was more evenly distributed across the model, seen in Figure 6.12. Large portions of the assembly are experiencing close to zero stress with a few localised areas bearing the tensile load. 
Seen in Figure 6.13 overleaf, the largest deformation occurs around the front bolt hole as seen in the compressive analysis, however the degree of deformation is larger for the same reasons mentioned previously.

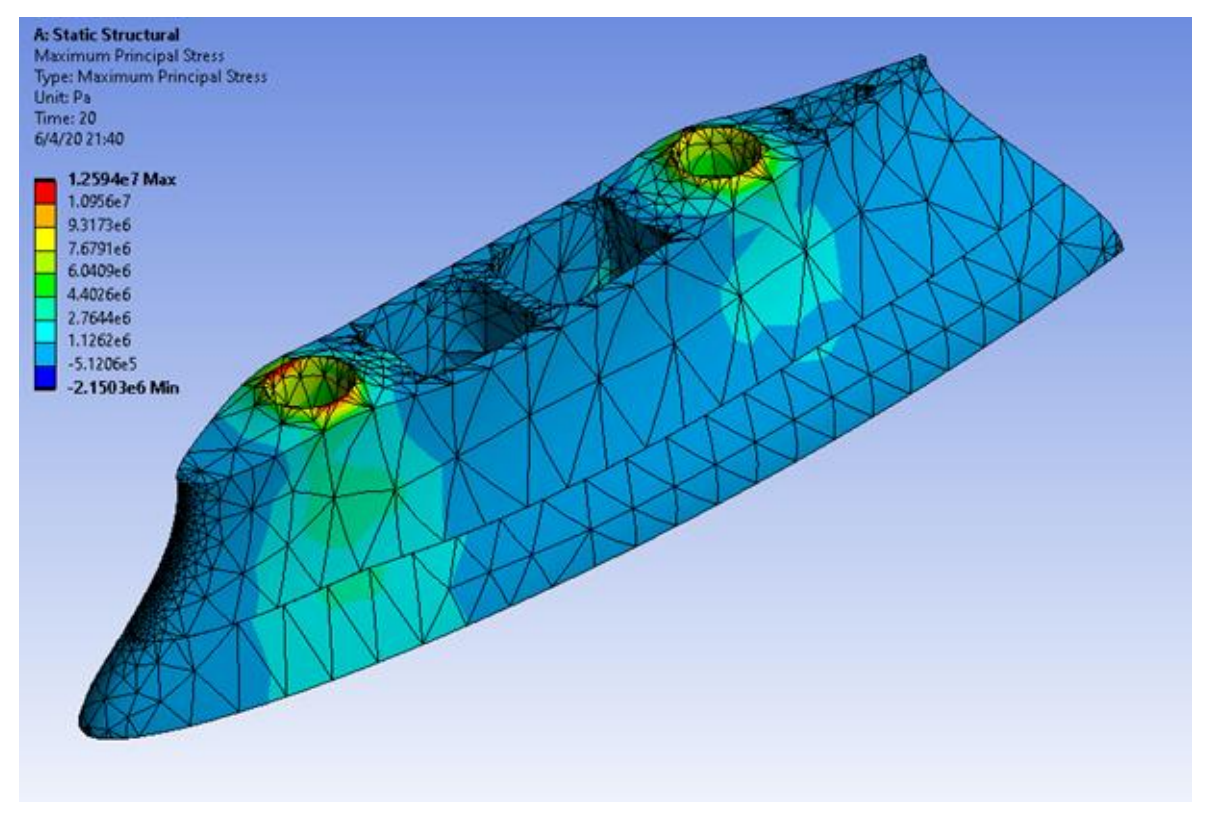

Figure 6.12 - Tensile Stress OF FASt MeSh

TABLE 6.4 - SUMMARY OF TENSILE LOADS

\begin{tabular}{|l|l|l|l|l|l} 
& \multicolumn{1}{l}{ Fast } & \multicolumn{1}{l}{ Slow } & \multicolumn{1}{l}{ Avg } & \% diff & \% of yield \\
\hline Max Stress (MPa) & 13.64 & 12.45 & 13.0 & 8.7 & 6.17 \\
\hline Avg Stress (MPa) & 1.35 & 1.53 & 1.44 & -13.4 & 0.68 \\
\hline Avg Shear $(\mathrm{KPa})$ & -0.61 & -25.09 & -12.9 & -4040.4 & - \\
\hline Max Def $(\mathrm{mm})$ & 0.0018 & 0.0014 & 0.0016 & 25.7 & - \\
\hline
\end{tabular}




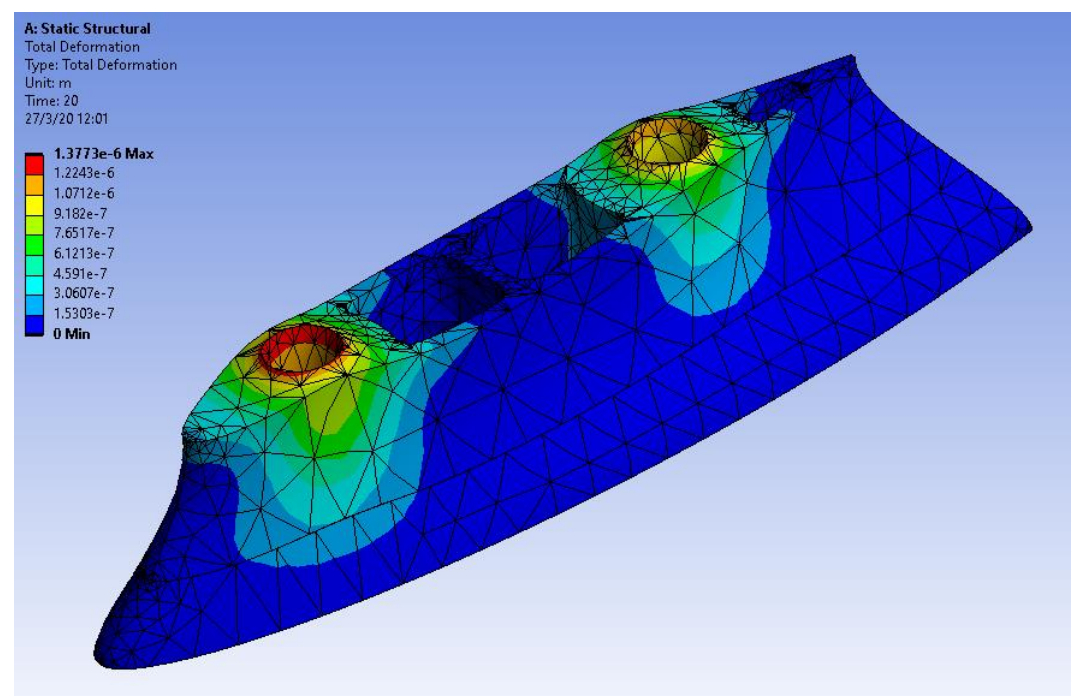

Figure 6.13 - Tensile Deformation of FASt MeSh

\section{Lateral Loading}

When the analysis torque of $241 \mathrm{Nm}$ is applied to the bolt holes and upper surface, the adapter experiences a peak stress of $158 \mathrm{MPa}$ averaged across both Slow and Fast meshes, which is $73.4 \%$ of the allowable yield strength of Al 6061-T6. This data is summarised in Table 6.5 overleaf.

Unexpectedly, the highest stress occurs along the upper front surface of the adapter, with small points of high stress inside the upper mass reduction holes, seen in the stress distribution in Figure 6.14 to the left. This shows that, if the adapter was exposed to intense lateral loads, the surface of the adapter would develop visible cracks before the bolt holes would begin to plastically deform.

Like previous results, the highest stress and deformation occur in the forward section of the adapter. Thus, material can be removed from the rear of the adapter, however as previously mentioned this is not possible due to interference with the thumb release mechanism. 


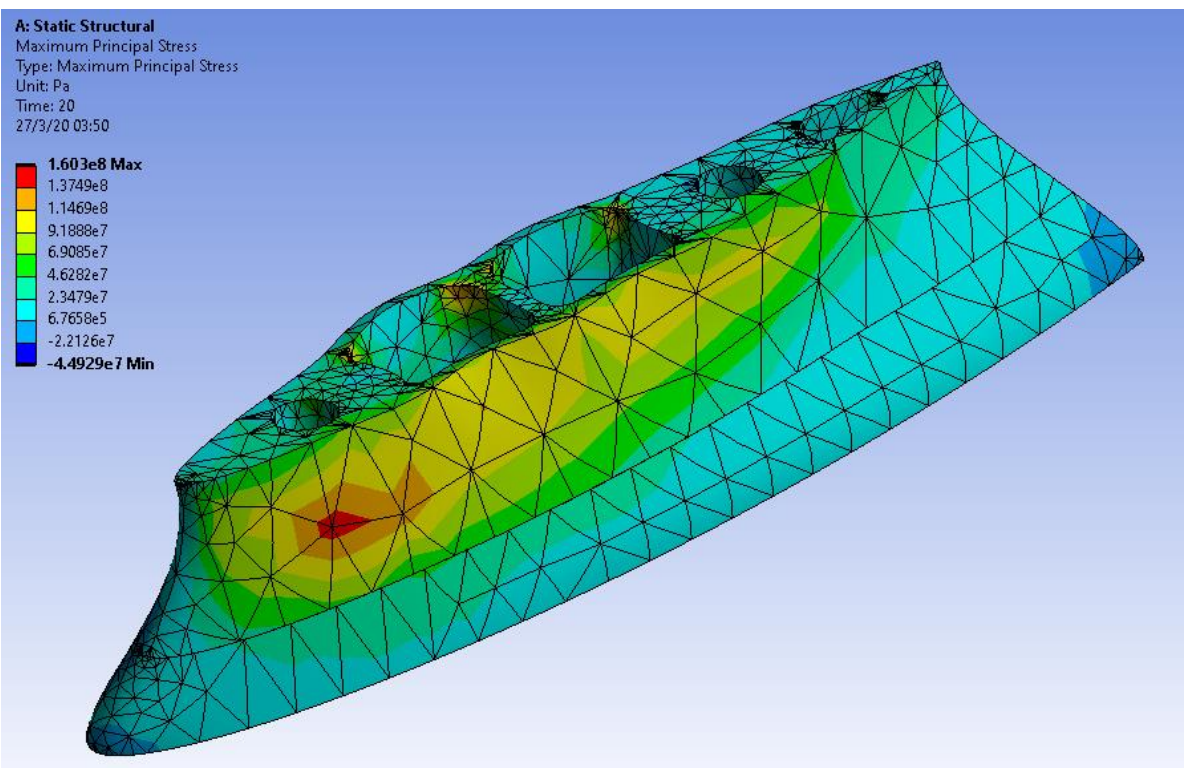

Figure 6.14 - LATERAL Stress OF FASt MeSH

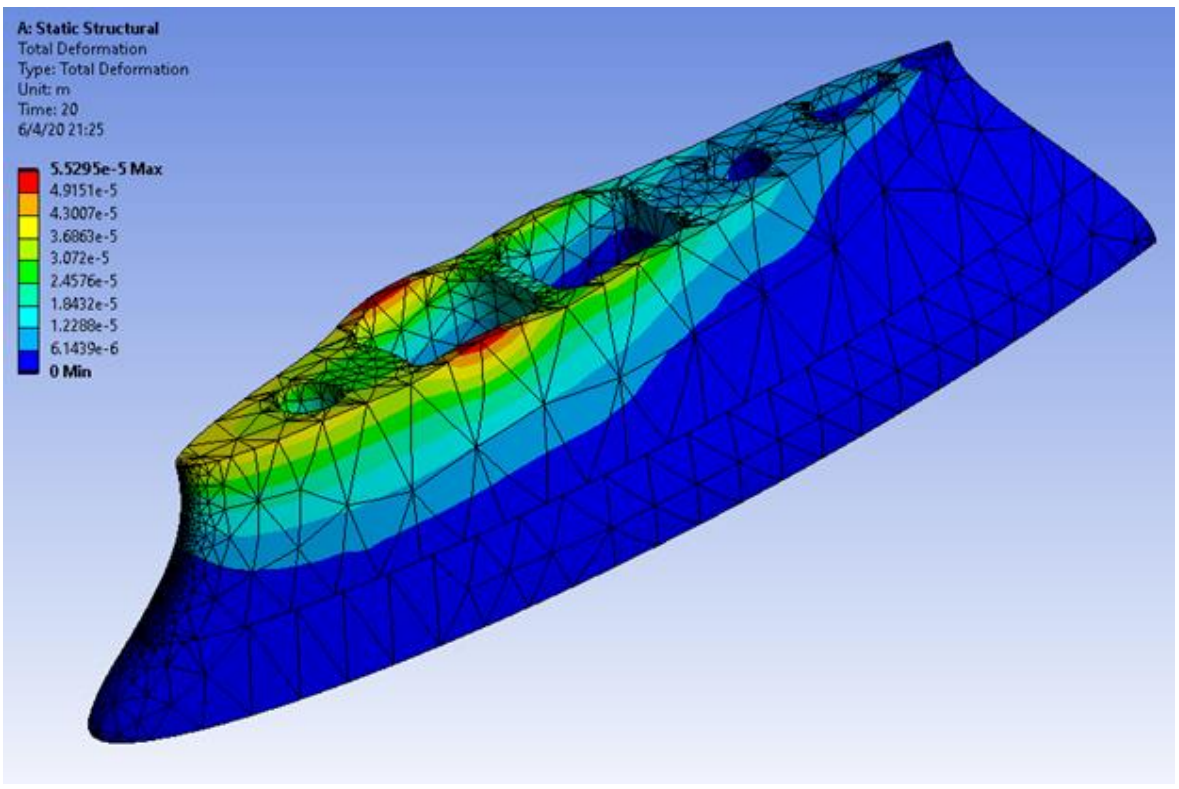

Figure 6.15 - Lateral Deformation of Fast Mesh 
TABLE 6.5 - SUMMARY OF LATERAL LOADS

\begin{tabular}{|c|c|c|c|c|c|}
\hline & Fast & Slow & Avg & $\%$ & $\%$ of yield \\
\hline $\begin{array}{ll}\text { Max } & \text { Stress } \\
(\mathrm{MPa}) & \end{array}$ & 160.30 & 172.10 & 166.20 & -7.4 & 78.60 \\
\hline $\begin{array}{l}\text { Avg } \\
(\mathrm{MPa})\end{array}$ & 16.84 & 18.39 & 17.62 & -9.2 & 8.33 \\
\hline Avg Shear (MPa) & -3.28 & -5.05 & -4.17 & 254.0 & - \\
\hline Max Def (mm) & 0.062 & 0.063 & 0.063 & -2.3 & - \\
\hline
\end{tabular}




\subsection{Fatigue Analysis}

One of the primary objectives was to ensure that the design is sufficiently fatigue resistant for it to replace the standard two bolt solution. The vertical and lateral analyses were repeated using the ANSYS Workbench Fatigue Tool to determine the safety factor of the design in each direction of loading. Boundary conditions are kept the same as previous static analysis. It is unreasonable to conduct fatigue analysis at the worst-case scenarios looked at previously. As such, each of the loads used were multiplied by 0.7 for fatigue analysis. The fatigue tool settings are shown in Table 6.6. The results of analysis are summarised in Table 6.7.

TAble 6.6 - Workbench Fatigue Tool Parameters

\begin{tabular}{l|l}
\hline Loading Type & Fully Reversed \\
\hline Analysis Type & $4.434 \mathrm{E}+05$ \\
\hline Mean Stress Theory & Goodman \\
\hline Stress Component & Equivalent (von-Mises) \\
\hline
\end{tabular}

As expected, the design is rock solid regarding vertical loading fatigue. The lateral axis is rated to $4.434 \times 10^{5}$ cycles. The fatigue results of lateral analysis were used to plot $\mathrm{S} / \mathrm{N}$ curves which is shown in Figure 6.16 overleaf.

TAble 6.7 - Summary of Fatigue Analysis Results

Cycle Life Safety Factor Alternating Stress (MPa)

\begin{tabular}{l|l|l|l}
\hline Vertical & $1.00 \mathrm{E}+09$ & $>15$ & 4.59 \\
\hline Lateral & $4.434 \mathrm{E}+05$ & 0.41 & 201.8 \\
\hline
\end{tabular}


Fatigue Sensitivity

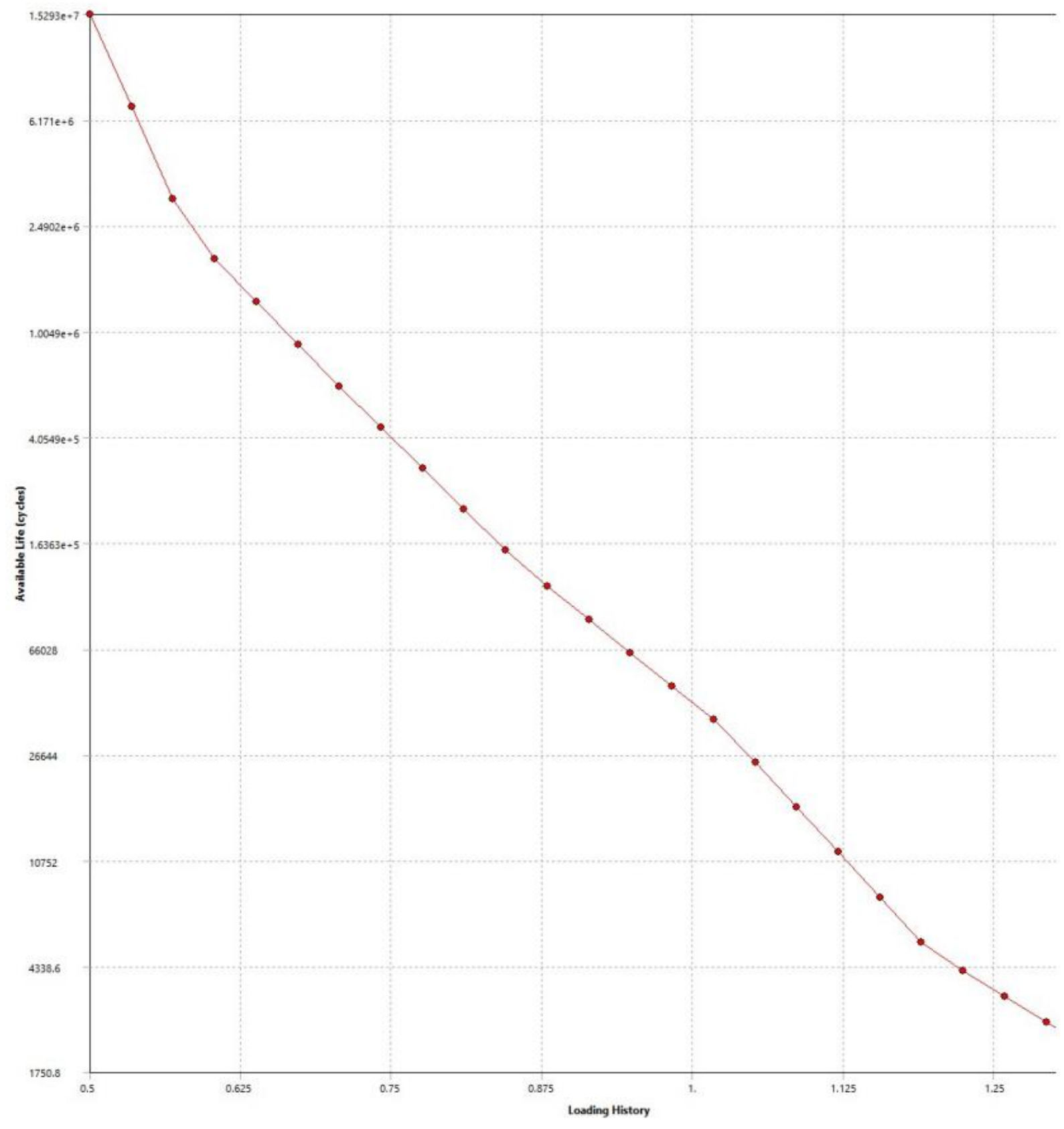

FigURE 6.16 - FATIGUE ANALYSIS OF LATERAL LOADING 


\section{Conclusion and Future Improvements}

\subsection{Summary of Design Work}

When initially starting this project, some objectives which were to be achieved during the design and analysis of a quick attach mechanism for a surfing hydrofoil. To achieve these objectives, firstly a literature review was conducted to obtain market research on existing quick attach designs, and design inspiration was obtained from both the hydrofoil and the rifle industry. From this, design objectives were laid out, and a series of design metrics were created to serve as a framework for design concept selection. Eight concepts were generated, and the best one chosen featured a rifle magazine inspired sliding dovetail joint attachment method.

The design chosen weighed 104g using Al 6061-T6, severely undercutting other quick attach designs on the market. Loading cases were conceptualised and the design was analyses using this loading data, and it was found to be very strong in compressive and tensile loading, experiencing $2.06 \%$ and $6.8 \%$ of allowable yield stress respectively, and experienced $73.4 \%$ of allowable yield stress in lateral loading. Upon fatigue analysis the design is capable of withstanding $1 \times 10^{9}$ and $8.769 \times 10^{5}$ cycles in compressive/tensile and lateral loading respectively.

\subsection{Scope for Future Work}

- Design a bracket or other mounting system to enable attachment of the adapter to the board directly. With a design like this, there could be quick connects on both ends of the mast, resulting in extremely simple and fast assembly of a foil. 
- During lateral and tensile loading the trailing edge of the adapter was found to bear very little load and as such could be shaved down even further given a different latching mechanism was devised.

- Modify the base of the adapter to make it 'universal', in other words make it compatible with any existing fuselage/mast interface on the market. This would allow the adapter to become a standalone product, as opposed to being specific to one design. 


\section{Appendix}

\section{Design Iterations}

Iteration 1

The first iteration was primarily a test of the procedure to create dovetail joints on non-planar surfaces in Solidworks and was quickly redesigned when hydrodynamics and the overall appearance of the apparatus were taken into consideration. Iteration 1 is shown in Figure 15, and is very basic. Only the upper portion of the apparatus was sketched, again primarily as a analysis run. It massed $117 \mathrm{~g}$. It featured two M8 bolt holes for attachment to the mast mounted on top, and a slot between the bolts for weight reduction.

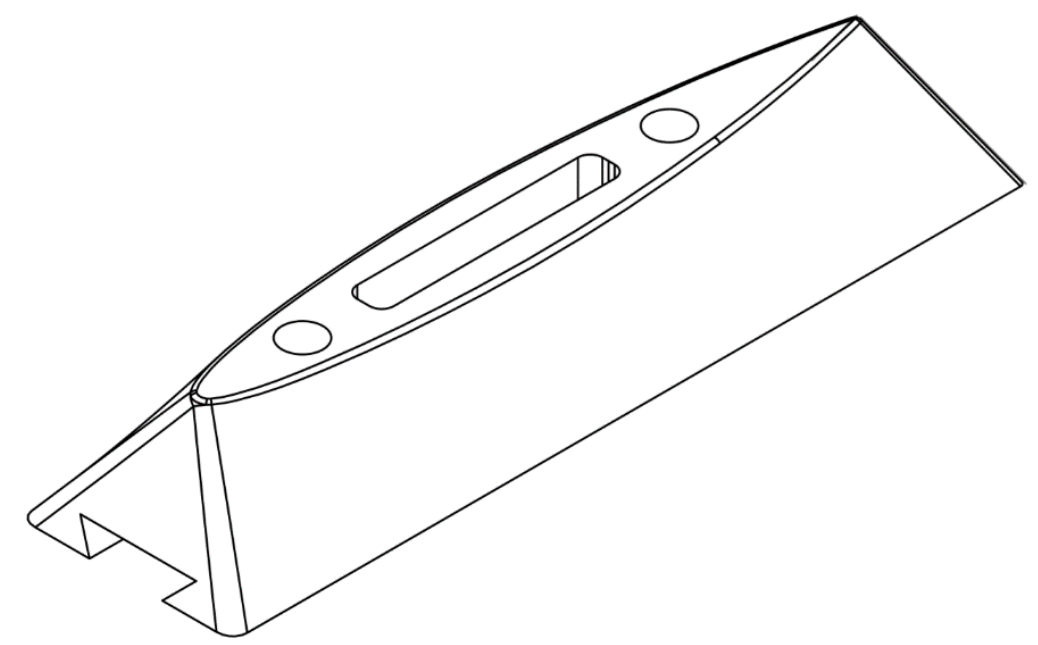

FigURE 9.1 - DESIGN ITERATION 1 


\section{Iteration 2}

In design iteration 2 , the design has been heavily streamlined to meet the secondary hydrodynamics and looks goals outlined in the introduction. The iteration is shown in Figure 16.

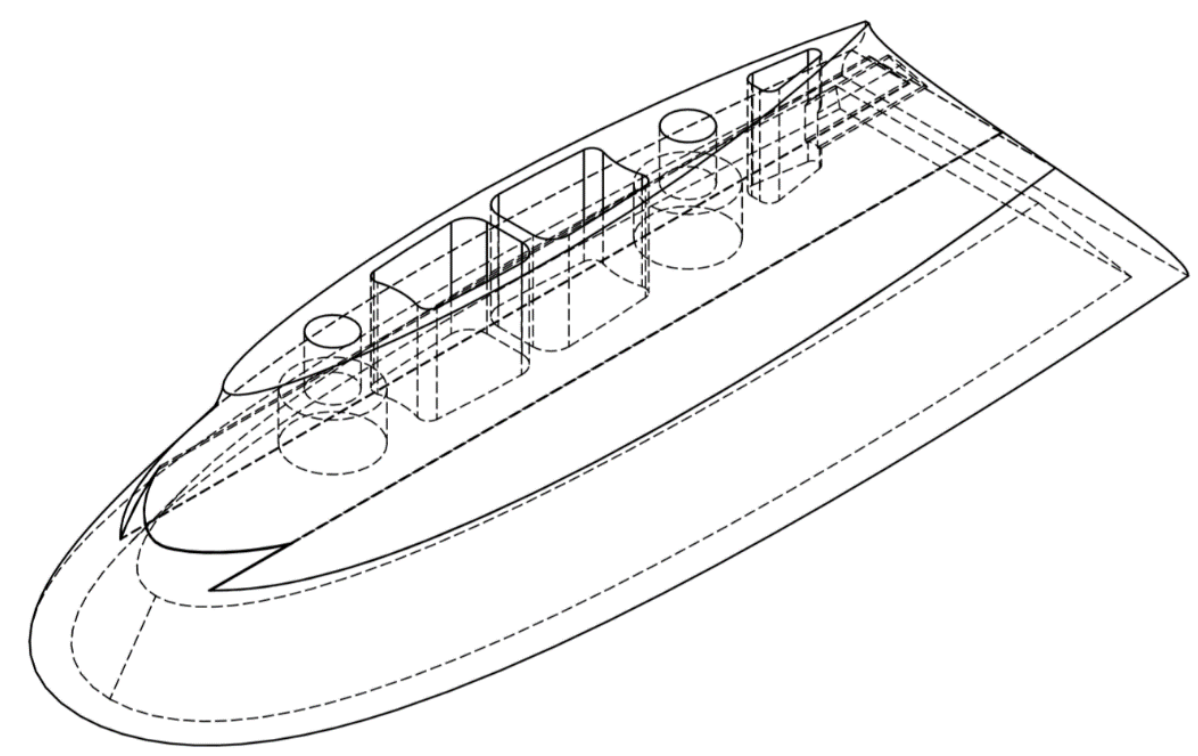

FIgURE 9.2 - DESIGN ITERATION 2

This design iteration massed $283 \mathrm{~g}$ including both upper and lower portions. It was determined at this point that a design under $200 \mathrm{~g}$ should be possible as this iteration was considered to be overdesigned. Several changes were made during this design iteration:

- The overall shape of the mast attachment has been rounded and streamlined for both looks, and drag and turbulence reduction.

- The central weight reduction holes have been redesigned to match those of the mast.

- The bolts in the upper attachment have been redesigned such that two M8 socket head bolts can be installed flush into the upper surface of the dovetail.

- A weight reduction pocket was milled out of the lower surface. 
- Cavities for the rear switch mechanism have been added.

\section{Iteration 3}

This iteration further improved on the previous one by significantly reducing weight while still meeting the physical analysising requirements.

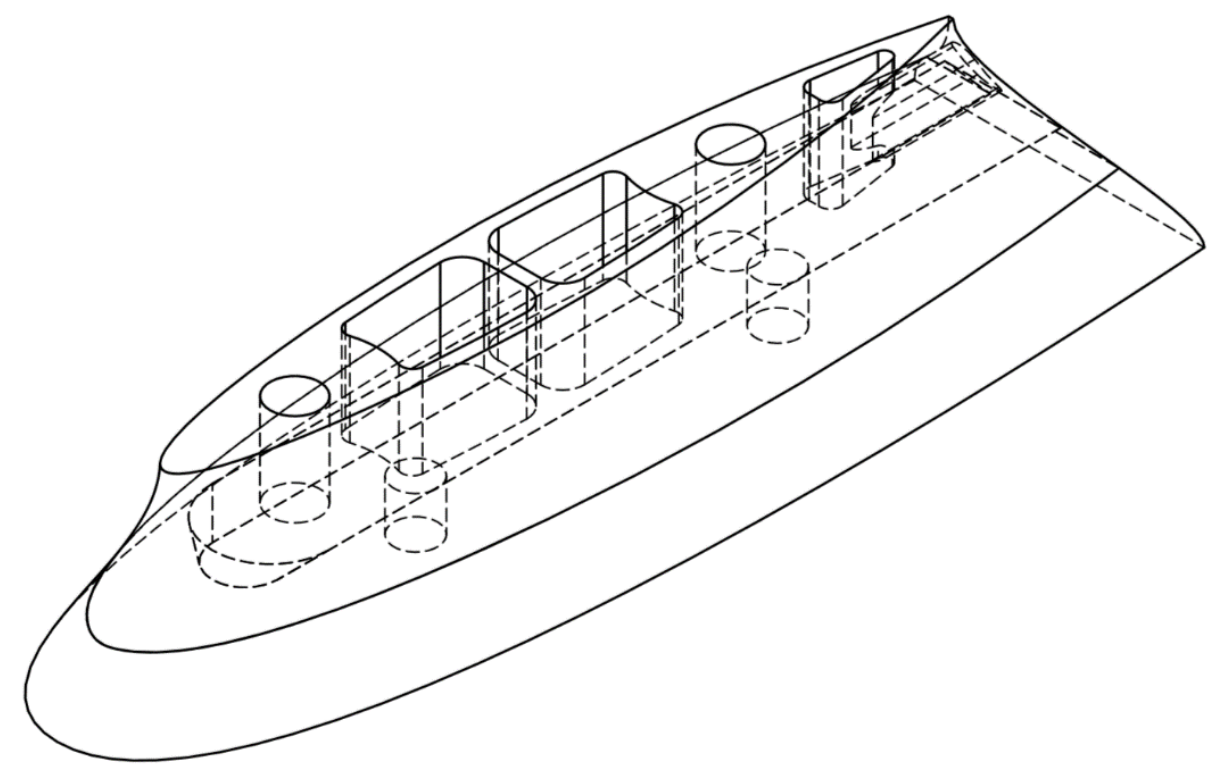

Figure 9.3 - Design Iteration 3

Iteration 3, shown in Figure 17, has undergone many minor tweaks from the previous iteration:

- The design has overall been streamlined and thinned out to reduce weight. The final mass was $187 g$.

- The cavity for the rear spring mechanism has been redesigned, and largened to provide a larger thumb switch.

- M6 mounting holes have been added to the lower surface of the apparatus to facilitate attachment to the wing; the lower mass reduction area has hence been removed. 
- The dovetail joint has been narrowed, and cut off on the interior of the design to:

- Increase manufacturability of the dovetail. The current design can be easily machined on a CNC milling maching using a dovetail cutter.

- Provide a stopping and locking point for the dovetail. 


\section{References}

[1] T. Klarich, "Adventures in Water Skiing: The Ride of my Life; Part 4, Hydrofoiling," 2012. [Online]. Available: http://tonyklarich.com. [Accessed November 2019].

[2] Liquid Force Kites, "Quick Release (QR) Collar," Dec 2019. [Online]. Available: https://liquidforcekites.com/product/quick-release-qr-collar/. [Accessed 2019].

[3] Noir Matter, "Quick Flight System," Dec 2019. [Online]. Available: https://noirmatter.com/products/quick-flight-system. [Accessed Nov 2019].

[4] North Shore Inc, "Fast Mast Hydrofoil Quick Release," Dec 2019. [Online]. Available: https://www.northshoreinc.com/store/pc/viewPrd.asp?idproduct=453. [Accessed Nov 2019].

[5] D. Heyden, "24, 5'11", and 169 Pounds: The Perfect Age, Height, and Weight for Pro Surfing," theinertia.com, 19 March 2018. [Online]. [Accessed November 2019].

[6] FoilMount, "FoilMount Hydrofoil Mounting Position Guide," FoilMoint, 29 July 2017. [Online]. [Accessed November 2019].

[7] Surfing Waves, "What Size Surfboard Do I Need?," Surfing Waves, April 2011. [Online]. Available: https://surfing-waves.com/board/board_size.htm. [Accessed November 2019].

[8] The Engineering Toolbox, "Factors of Safety for Engineering Design," 2010. [Online]. Available: From https://www.engineeringtoolbox.com/factors-safety-fos-d_1624.html. [Accessed November 2019].

[9] H. Hrachya, "AK-47, AKM/AKMS and AK-74 Blueprints," 3 April 2017. [Online]. Available: https://www.thefirearmblog.com/blog/2017/04/03/ak-47-akmakms-ak-74-blueprints/. [Accessed Nov 2019]. 
[10] G. Chesnut, Cartridge Magazine for Use With a Plurality of Firearms, Golden, Colorado: United States Patent Office, 1986.

[11] Seabreeze.com.au, "How to make your own Hydrofoil," Seabreeeze.com.au, August 2016. [Online]. Available: $\quad$ https://www.seabreeze.com.au/News/Kitesurfing/How-to-make-your-ownHydrofoil_8649403.aspx. [Accessed October 2019]. 